\section{La cattedrale e la città: il cantiere del Duomo di Siena. Risultati delle indagini archeologiche}

\section{The cathedral and the city: the building workshop of Siena's Duomo. Results from archaeological researches}

\section{Marie-Ange Causarano}

Dipartimento di Archeologie e Storia delle Arti.

Università degli Studi di Siena*

\begin{abstract}
Riassunto
Il contributo tratta degli studi condotti nell'ultimo decennio all'interno della cattedrale di Siena. Le indagini geologiche condotte nella collina del Duomo e lo scavo stratigrafico svolto in alcuni locali situati sotto il coro e il transetto della cattedrale hanno evidenziato lo stratificarsi delle fasi di vita che, dal periodo ellenistico, hanno interessato quest'area della città. A queste ricerche si è affiancato lo studio dello sviluppo del Duomo tra XI e XV secolo, condotto tramite I'analisi diretta dell'architettura e dei suoi materiali: i dati provenienti dalle indagini di scavo e dallo studio degli elevati hanno permesso l'individuazione delle principali trasformazioni subite dalla parte absidale del monumento tra XI e inizio XVIII secolo. L'analisi degli elevati svolta sulle murature del cleristorio ha permesso inoltre di comprendere l'organizzazione del cantiere che procedette nella costruzione delle navate e le trasformazioni subite dal corpo basilicale tra la seconda metà del XIII secolo e la metà del XIV secolo. L'individuazione delle principali tecnologie costruttive impiegate nella cattedrale tra XI e XV secolo, lo studio dei metodi, delle tecniche e degli strumenti di lavorazione utilizzati, hanno portato nuovi dati sull'ambito culturale di formazione delle maestranze all'opera nel Duomo.
\end{abstract}

Parole chiave: Stratigrafia; tecniche costruttive; organizzazione del cantiere; tracce di lavorazione; maestranze.

\section{Abstract}

This paper deals with the studies carried out in the cathedral of Siena in the last decade. Geological surveys on the hill of the «Duomo» and stratigraphical excavations of some rooms placed directly underneath the choir and the transept have shown evidence of continued settlement in this part of the town from the Hellenistic period onwards. The analysis of the development of the cathedral between the 11th and 15th centuries has been based on a direct analysis of the architecture and building materials. Data from excavations and from the analysis of the standing walls show the main transformations which have taken place at the apse of the monument between the 11 th and the early 18 th centuries. The analysis of the walls of the clerestory allowed to understand the organization of its construction related to the building of the naves and the transformations of the basilican building between the second half of the 13 th and mid 14th centuries. The identification of the main building technologies used in the cathedral between the 11 th and 15th centuries, together with the study of methods, techniques and tools employed in the construction process, have brought new data on the cultural environment in which the specialised craftsmen of the cathedral were trained.

Keywords: Stratigraphy; building techniques; masonry workshop's organization; working traces; masters.
Nel 1999 l'Opera Metropolitana di Siena ha avviato il progetto di restauro di un complesso di ambienti sottostanti e in parte adiacenti alla cattedrale, costituenti l'ex oratorio dei Ss. Giovannino e Gennaro: durante le indagini preliminari, furono scoperte alcune grotte scavate nelle sabbie plioceniche della collina del Duomo, riempite di detriti, e un cunicolo che conduceva ad un ambiente anch'esso completamente ingombro di materiale di riempimento, situato al di sotto del pavimento della cattedrale, nell'area del transetto compresa tra la cupola ed il coro ${ }^{1}$.

L'anno seguente, su richiesta ed in collaborazione con l'Opera Metropolitana, l'Insegnamento di Archeologia Medievale dell'Università di Siena ha iniziato le indagini ${ }^{2}$, finalizzate nella fase iniziale al controllo e al vaglio dei livelli di riempimento di terra e materiale edilizio individuati nel vano situato al di sotto del coro della cattedrale. Dal 2003, terminato lo svuotamento di questo ambiente e la messa in sicurezza del ciclo di affreschi venuto alla luce durante i lavori ${ }^{3}$, si è iniziato lo scavo stratigrafico dell'area. Parallelamente a queste indagini, è iniziato lo studio degli elevati negli ambienti adiacenti al vano interrato, al fine di comprendere lo sviluppo e le trasformazioni della parte absidale del Duomo (Causarano et al. 2003; Causarano 2005). La ricerca è proseguita con lo studio delle murature visibili nei sottotetti delle navate laterali, della cupola e del campanile al fine di approfondire lo studio sull'evoluzione dell'edificio religioso tra la metà del XIII ed il XIV secolo (Causarano 2009).

\section{LE INDAGINI ARCHEOLOGICHE NELLA COLLINA DEL DUOMO}

L'Insegnamento di Archeologia Medievale dell'Università di Siena, sebbene impegnato prevalentemente in indagini sulle dinamiche insediative e produttive nella Toscana centro-meridionale, ha svolto numerose ricerche anche nel contesto urbano senese ${ }^{4}$.

Grazie all'avvio del primo cantiere di scavo urbano, aperto nella piazza antistante la cattedrale di Siena e l'Ospedale del Santa Maria della Scala, il grande complesso medievale situato lungo il versante meridionale della

\footnotetext{
${ }^{1}$ Per le problematiche relative all'intervento di restauro dell'oratorio e dei locali sottostanti il coro del Duomo, si veda Bratto 2003.

${ }^{2}$ Le indagini ed i lavori relativi allo svuotamento ed al restauro del vano affrescato sono stati seguiti da una commissione scientifica appositamente incaricata dall'Opera Metropolitana di Siena; alla commissione partecipavano per le indagini archeologiche - il prof. Riccardo Francovich ed il prof. Marco Valenti.

${ }^{3}$ Questa prima fase di indagini, culminata con l'apertura al pubblico del vano rinvenuto sotto al coro del Duomo, è edita in Guerrini 2003.

${ }^{4}$ Per un quadro generale delle indagini svolte nel contesto urbano senese, si veda Francovich 2005; Francovich, Valenti 2006; Cantini et al. 2006.
} 

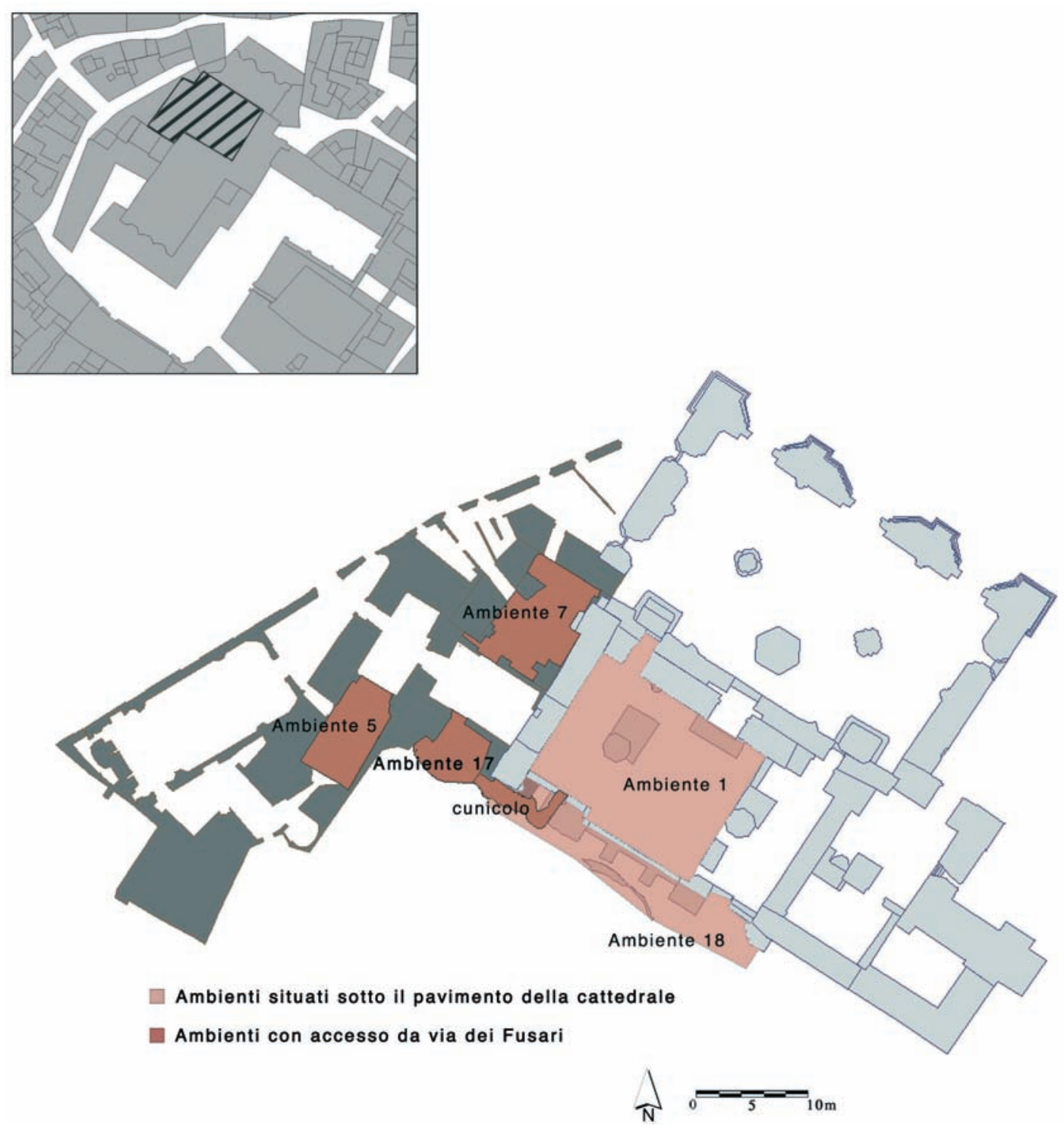

Fig. 1. Pianta del transetto e del coro della cattedrale di Siena (piattaforma GIS della città di Siena). In alto a sinistra, in evidenza le aree interessate dall'intervento archeologico

collina del Duomo, le indagini, a partire dalla fine degli anni Ottanta del secolo scorso, si sono concentrate in una delle aree di più antica frequentazione della città, la collina del Duomo (Boldrini, Parenti 1991). Alcuni anni dopo, alla fine degli anni Novanta, con il progredire dei lavori di restauro all'interno dell'Ospedale Santa Maria della Scala, fu aperto un secondo cantiere di scavo all'interno del monumento: $i$ dati emersi in questi anni di indagini comprendono un vasto arco cronologico che va dal VII-VI sec. a.C. fino all'età contemporanea e, analogamente a quanto emerso nello scavo di piazza Duomo, le informazioni sono risultate particolarmente importanti soprattutto per i secoli non documentati dalle fonti scritte, specialmente per quanto riguarda la tipologia di insediamento presente tra la fase repubblicana ed il medio impero ed i processi di trasformazione intercorsi nel tessuto insediativo di questa parte di città tra tardoantico $e$ altomedioevos.

A questi dati, inerenti il versante meridionale della collina del Duomo ed un breve tratto di porzione sommitale, si sono aggiunti in anni recenti i risultati dell'intervento archeologico condotto sotto la cattedrale di Siena, che ha indagato parte del versante nord-occidentale del colle e una limitata porzione del pianoro superiore, area poi occupata dalla parte absidale del Duomo (Fig. 1).

${ }^{5}$ I risultati delle indagini archeologiche sono stati divulgati nel 2002 (L'Ospedale Santa Maria della Scala 2002). Recentemente è stata pubblicata l'edizione delle fasi altomedievali rinvenute al di sotto dell'Ospedale (Cantini 2005); per una sintesi dei rinvenimenti archeologici, si veda Francovich, Valenti 2006; Cantini et al. 2006. 


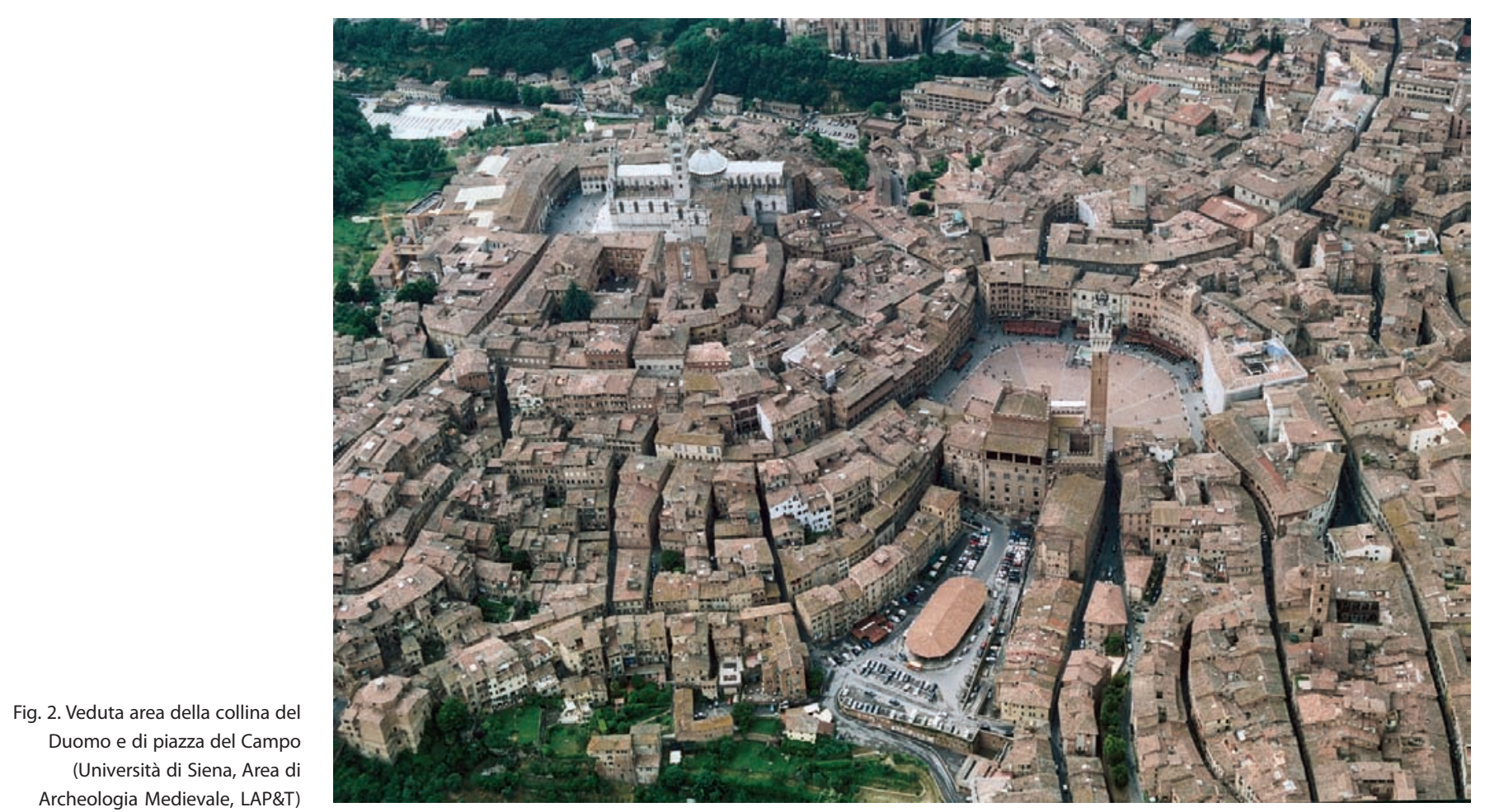

\subsection{Geomorfologia della collina del Duomo di Siena}

Siena si trova al centro di un vasto paesaggio collinare, tra le valli dei fiumi Arbia a sud, Merse a sud-ovest ed Elsa a nord; tra le colline del Chianti a nord-est, la Montagnola ad ovest e le Crete Senesi a sud-est. Il paesaggio collinare della città si è formato essenzialmente dall'incisione fluviale di un pianoro, composto da sedimenti marini sabbiosi e sabbioso-argillosi con banchi di conglomerato, che si è sollevato - a partire dal Pleistocene medio - per più di 300 metri (Bossio et al. 1995). Il territorio sul quale si è sviluppata è assimilabile dunque ad una sorta di «altopiano» $\mathrm{i}$ cui bordi sono marcati da profonde anse di erosione.

Su questo altopiano si possono identificare tre crinali principali, che si incontrano a formare una $\mathrm{Y}$, con quota massima di $350 \mathrm{~m}$ s.l.m.: appartengono ad una serie di rilievi costituiti da formazioni plioceniche marine, sabbiose in alto, argillose in basso. Le sabbie plioceniche formano uno strato piuttosto compatto e relativamente permeabile, impropriamente detto "tufo», con intercalazioni di argilla e ciottoli: costituiscono il litotipo più diffuso nell'area del centro storico e si alternano a banchi di conglomerati poligenivi (puddinghe).

Lalternanza di resistenti strati di conglomerato e di strati sabbiosi permeabili è alla base della morfologia della città, composta da versanti ripidi e sommità lievemente ondulate. I tre colli sui quali sorge Siena hanno, infatti, una caratteristica struttura a gradoni naturali, detti costoni (o coste): proprio questa particolarità morfologica è alla base della forma e delle modalità di sviluppo urbanistico della città e dell'organizzazione della sua viabilità (Fig. 2).

In base ai dati provenienti dalle analisi pedologiche e dagli studi geologici condotti nell'area della cattedrale ${ }^{6}$, è ipotizzabile che la collina del Duomo apparisse, in epoca pre-urbana, con un'altura sommitale leggermente inclinata, concava in corrispondenza delle linee di deflusso delle acque superficiali': per l'individuazione del profilo originario del colle, si è rilevato di particolare importanza il rinvenimento - durante le indagini archeologiche condotte negli ambienti sottostanti il coro del Duomo di Siena - di due tratti di paleosuoli (porzioni di superficie alterata ma

\footnotetext{
${ }^{6}$ Nel 1989 è iniziato lo studio geologico dell'area circostante il Duomo di Siena, finalizzato alla caratterizzazione geotecnica, statica e dinamica dei terreni di fondazione ed alla definizione del loro assetto strutturale (Costantini 1999; Censini et al. 1993). In occasione delle indagini archeologiche condotte a partire dal 1998 nello Spedale del Santa Maria della Scala e, a partire dal 2000, nel Duomo di Siena, sono stati inoltre condotti studi specifici sui profili originari dei terrazzamenti di Siena (Pallecchi 2004-05), sulla configurazione spaziale e il 'profilo' pre-urbano della collina del Duomo (Arnoldus-Huyzendveld 2002). ${ }^{7}$ Arnoldus-Huyzendveld 2002, pp. 12-13. Intorno alla sommità si doveva trovare un primo salto di quota, posto a quote comprese tra i 336 ed i $340 \mathrm{~m}$ s.l.m. sui lati nord e nord-est del colle ed i 338-341 m s.l.m. sul lato nord-ovest; al di sotto si trovava un tratto sommitale più basso, inclinato o moderatamente ripido, tendenzialmente convesso. Nelle zone poste invece sopra l'inizio delle incisioni vallive più profonde, iniziava il tratto di pendio più ripido: la rottura di pendio era posta, come oggi, ad una quota intorno ai 325-327 m s.l.m.
} 


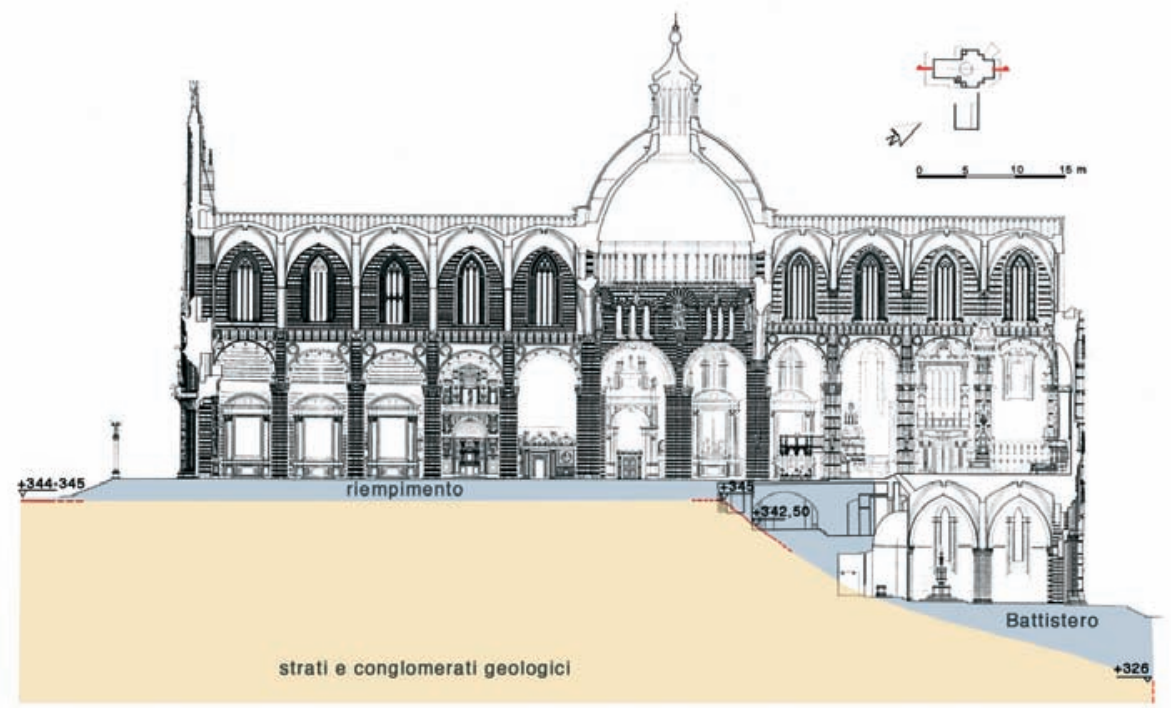

Fig. 3. Sezione longitudinale del Duomo di Siena (rilievo da Haas, von Winterfeld 2006) con ricostruzione della forma originaria della collina e l'individuazione dei paleosuoli non ancora intaccata dall'attività antropica) che hanno consentito l'individuazione della posizione e della pendenza originaria del versante nord-est della collina (Fig. 3).

\subsection{Gli interventi di scavo sotto il Duomo}

Le indagini sono iniziate con lo svuotamento dell'ambiente affrescato rinvenuto al di sotto del coro della cattedrale (Ambiente 1): il vano, a pianta rettangolare con una superficie di circa $160 \mathrm{mq}$, era completamente riempito da depositi di terra, materiale detritico e scarti di lavorazione databili tra la prima metà del XV secolo - data del definitivo abbandono dell'ambiente - e l'inizio del XVIII secolo $^{8}$.

I livelli di riempimento più recenti, formati da materiale di risulta, erano funzionali alla costruzione e alla successiva obliterazione di una serie di loculi in mattoni situati negli angoli nord-ovest e sud-ovest del vano: posti immediatamente sotto il piano pavimentale della cattedrale e poggianti sui livelli di riempimento sottostanti, erano dotati di una botola in legno che consentiva la deposizione dei defunti direttamente dal pavimento della cattedrale ${ }^{9}$ (Fig. 4).

${ }^{8}$ Causarano et al. 2003, pp. 153-155. Per la rimozione del materiale detritico, vista la particolare ubicazione del vano - situato sotto il pavimento della cattedrale - si è proceduto in una prima fase dall'alto verso il basso, fino ad asportare la metà superiore del riempimento; in seguito si è scavato per "pozzi» successivi in modo da garantire di volta in volta la posa in opera delle opere di sostegno. L'intera operazione ha richiesto circa un anno di lavoro e l'asportazione di più di $1000 \mathrm{~m}^{3}$ di materiale (per una descrizione dettagliata dell'intervento e della messa in sicurezza dell'ambiente, si veda Bratto 2003, pp. 185-188)

${ }^{9}$ Le sepolture scavate contenevano resti di inumati, alcuni dei quali conservatisi in stato di mummificazione spontanea a causa dell'atmosfera anaerobica dell'ambiente.
La parte inferiore del riempimento era costituita in prevalenza da materiale edilizio di scarto. In prossimità dell'abside del Battistero - che in parte taglia il muro di

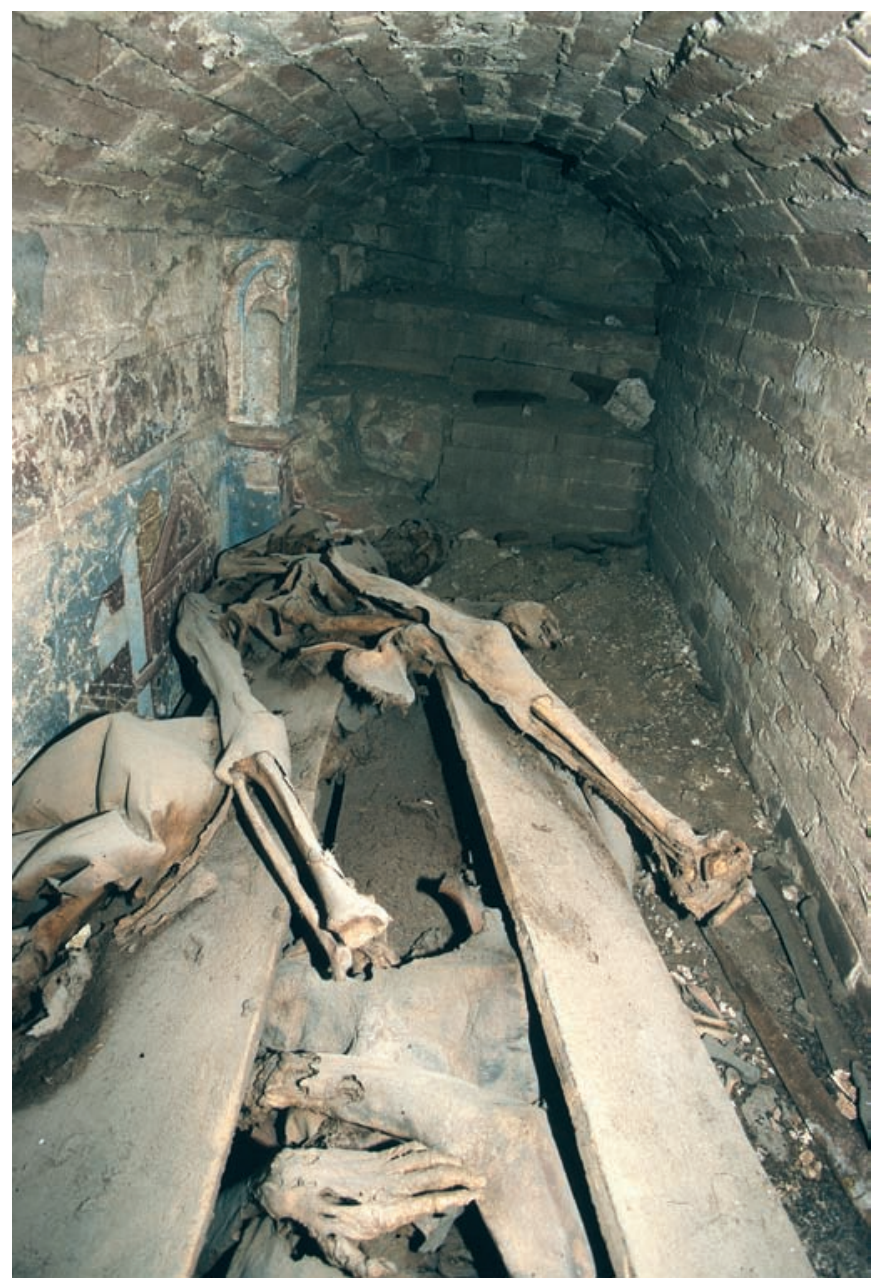

Fig. 4. Loculo in mattoni addossato agli affreschi 


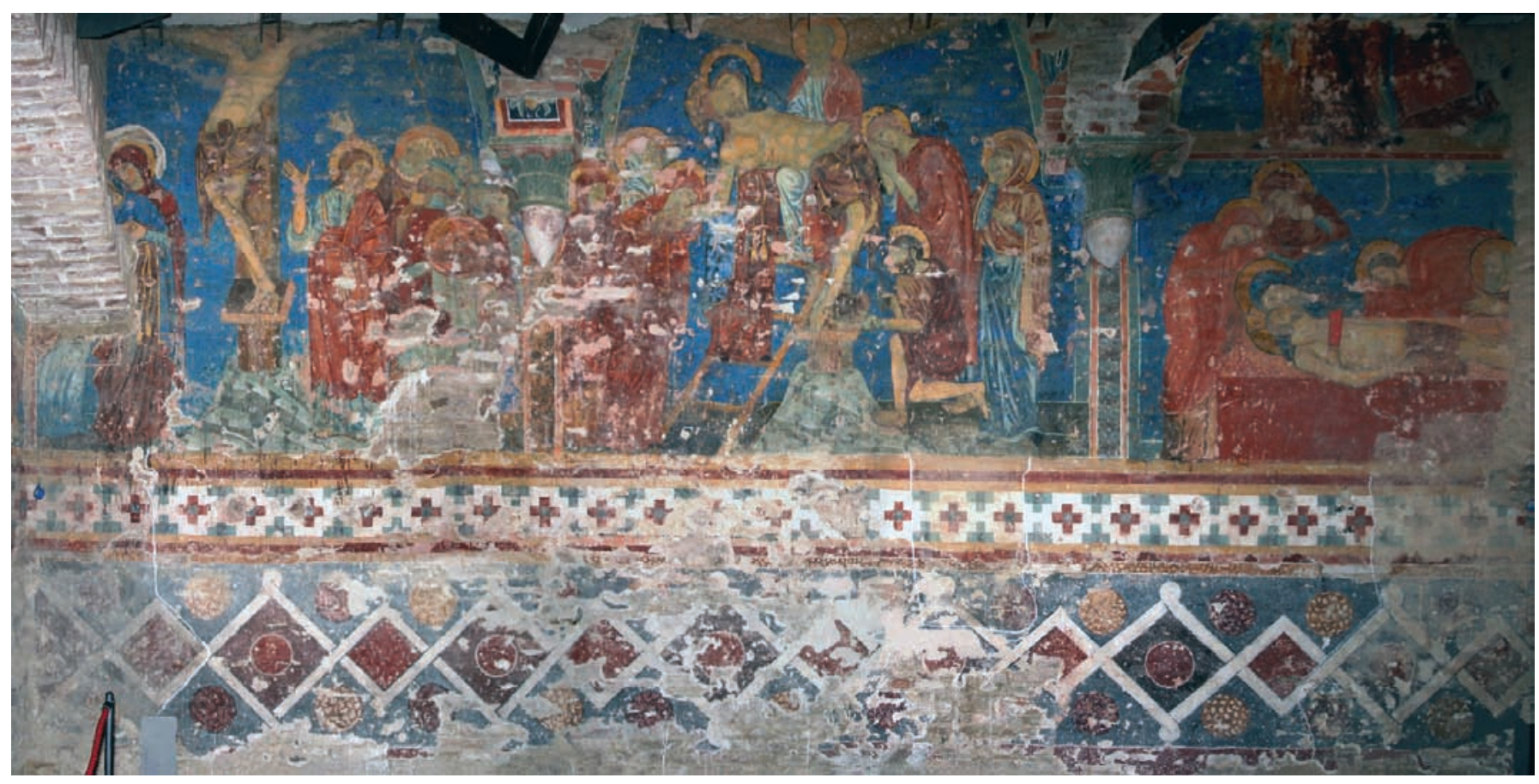

Fig. 5. Fotoraddrizzamento della parete sud-ovest con le scene della Passione (prima del restauro degli affreschi)

facciata dell'ambiente - si è trovata la maggiore concentrazione di reperti: frammenti di ceramica, oggetti in ferro e bronzo, monete ${ }^{10}$. Il riempimento è databile alla prima metà del XV secolo quando il vano, le cui volte erano state demolite probabilmente intorno al terzo quarto del XIV secolo per la costruzione di alcune strutture di rinforzo al Battistero e al coro della cattedrale, fu abbandonato definitivamente. La costruzione dell'abside del Battistero, databile agli anni '20 del Quattrocento, è l'ultimo intervento condotto al suo interno: nel muro costruito a protezione dell'abside ed in fase con essa, sono stati infatti ritrovati, ancora in posto, $i$ resti dei ponteggi in legno impiegati per la sua costruzione.

Procedendo con la rimozione dei livelli di riempimento è venuto alla luce un ciclo di affreschi che copriva per intero le pareti perimetrali dell'ambiente, con storie dell'Antico e del Nuovo Testamento giustapposte su due differenti registri ${ }^{11}$. Partendo dalla parete ovest e procedendo in senso orario, sono visibili da principio gli episodi del Paradiso terrestre, le storie mariane e l'infanzia di Cristo,

${ }^{10}$ L'ambiente anaerobico ha permesso la conservazione di reperti di natura organica, come ad esempio elementi in cuoio pertinenti a sandali, cinture, lacci e altri oggetti frammentari, tappi in sughero, un pettine, lembi di tessuto e semi. ${ }^{11}$ Bagnoli 2003. Le scene dell'Antico Testamento, sistemate nelle parti alte dei muri e con a disposizione uno spazio limitato, sono andate quasi totalmente perdute in seguito alla demolizione delle volte e della parte superiore delle pareti perimetrali dell'ambiente, mentre quelle del Nuovo Testamento, più largamente esposte sulle superfici sottostanti, si sono conservate quasi integralmente. per risalire poi a quelle di Caino e Abele, Isacco ed Esaù, scendere nuovamente agli episodi della vita pubblica di Cristo e arrivare infine al dramma della Passione, rappresentato dalle tre grandiose scene (Crocifissione, Deposizione dalla croce, Deposizione nel sepolcro) sulla parete di fondo dell'ambiente (Fig. 5).

Lo spazio interno era scandito dai due grandi pilastri ottagonali del coro, affrescati anch'essi, e da due colonne più piccole, di cui si sono conservate solo le basi in pietra, mentre il collegamento con il Duomo era assicurato da una scalinata, poi demolita, collocata nell'angolo nordovest del vano, pavimentato in laterizi. Si accedeva all'ambiente, coperto con volte a crociera costolonata, tramite tre ingressi aperti nella facciata posteriore della cattedrale, rivolta ad oriente (Fig. 6) ${ }^{12}$.

La rimozione del pavimento ha consentito il proseguimento delle indagini sul versante settentrionale della collina grazie allo scavo stratigrafico condotto in questo ambiente e in un locale ad esso retrostante (Ambienti 1 e 18); inoltre le indagini sono proseguite con lo scavo di alcuni vani (Ambienti 5, 6, 7 e 17) situati lungo il pendio occidentale, al di sotto del braccio sinistro del transetto trecentesco. Il deposito indagato ha rivelato la presenza di una sequenza ininterrotta compresa tra il periodo ellenisti-

\footnotetext{
${ }^{12}$ E' questa una delle scoperte di maggiore rilevanza che più ha contribuito alla comprensione dello sviluppo e delle modifiche di questo ambiente e di tutta la parte absidale della cattedrale (si veda infra, 2.2)
} 


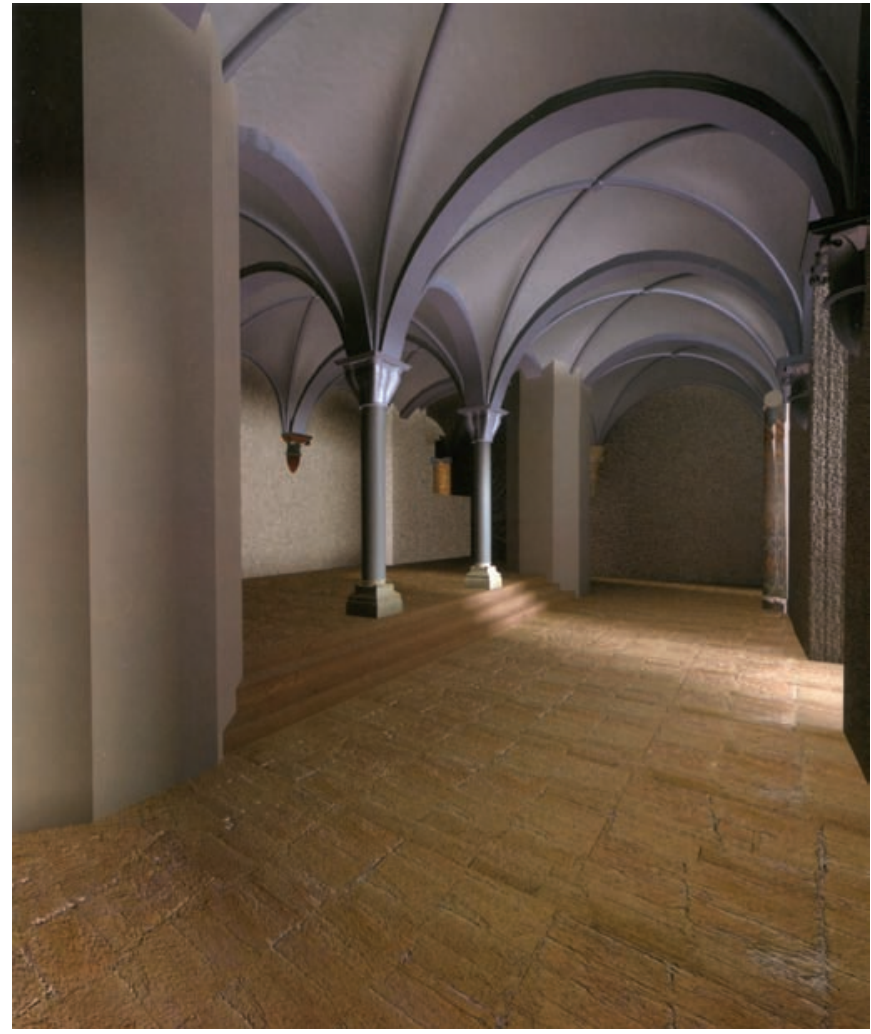

Fig. 6. Ricostruzione del vano affrescato: vista interna da nord con, in trasparenza, il sistema di volte e colonne (da Bratto 2003, fig. 17)

co e il primo altomedioevo ${ }^{13}$ : l'ampliamento verso nordovest della parte absidale della cattedrale nel XII secolo e l'ampliamento del braccio sinistro del transetto nel Trecento hanno infatti asportato la maggior parte delle stratigrafie più recenti.

Età ellenistica - I depositi stratigrafici accumulatosi lungo i pendii settentrionale ed occidentale del colle testimoniano la presenza di una frequentazione antropica fin dal periodo ellenistico: mentre il versante nord fu soggetto allo scarico e all'accumulo di materiale proveniente dalla sommità, il fianco ovest della collina, invece, fu regolarizzato grazie ad un grande taglio che, oltre ad aumentarne artificialmente la pendenza, creava una viabilità di risalita verso il pianoro superiore (Ambiente 17) ${ }^{14}$.

A breve distanza da questa rampa artificiale, è stato rintracciato un cunicolo facente parte di un impianto idrico scavato nelle sabbie plioceniche del colle (Fig. 7), che si sviluppa in direzione nord-sud per sfociare in un

\footnotetext{
${ }^{13}$ Una prima sintesi dei risultati di scavo in Causarano et al. 2003, pp. 153-159, ripresa e aggiornata poi in Causarano 2005, pp. 24-28 e in Cantini et al. 2006, pp. 285-289.

${ }_{14}$ Sulla realizzazione delle rampe di collegamento tra $\mathrm{i}$ gradoni naturali che scandiscono i colli su cui sorge Siena, si veda Pallecchi 2006, p. 585 e ss.
}

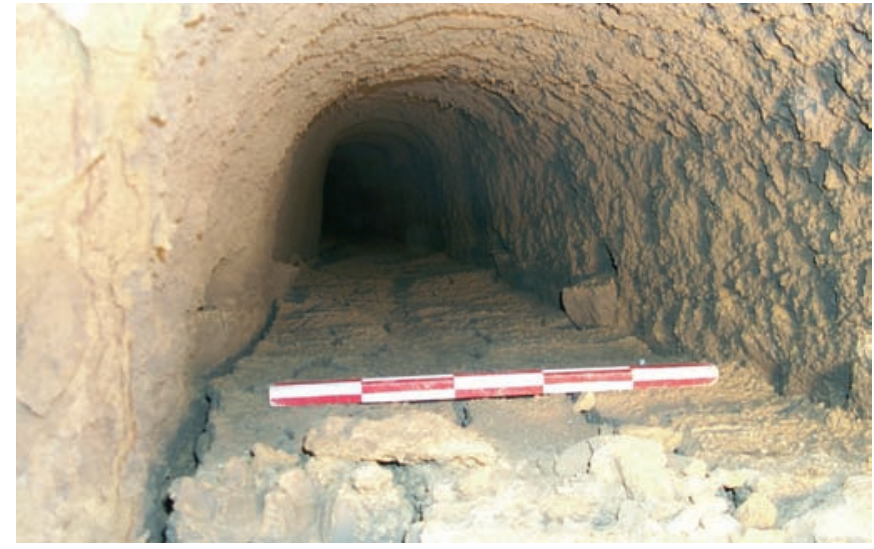

Fig. 7. Cunicolo realizzato in età ellenistica: in primo piano si notano le «pedarole», piccole cavità scavate nelle pareti di tufo funzionali alla discesa all'interno della struttura e all'alloggio di lucerne

pozzetto di decantazione delle acque, a pianta quadrata (Ambiente 5).

Età romana - Tra i numerosi materiali di epoca romana rinvenuti durante le indagini ${ }^{15}$, la concentrazione di reperti riferibili all'età imperiale lungo il pendio settentrionale del colle fa ipotizzare una maggiore antropizzazione dell'area in questo periodo.

Sul lato occidentale della collina la frequentazione di epoca romana è attestata invece dal riutilizzo del pozzetto di decantazione delle acque. L'impianto cessò di essere in funzione durante la prima età imperiale ${ }^{16} \mathrm{ma}$ fu recuperato e, utilizzato con scopi sacrificali, venne dotato di una copertura lignea. I livelli superiori di riempimento del pozzetto hanno dato, infatti, oltre a materiale ceramico, resti osteologici riferibili a quattro cani - due dei quali adagiati su un fianco e con tracce di macellazione lungo il tronco - e la parte anteriore dello scheletro di un cavallo (Fig. 8). Il rinvenimento sembra essere collegabile al rito propiziatorio, in uso già in età repubblicana, connesso alla fondazione delle mura e delle porte cittadine: l'opera di perimetrazione urbana veniva infatti sacralizzata attraverso il sacrificio di animali, di solito cani, e la loro inumazione rituale ${ }^{17}$.

\footnotetext{
${ }^{15}$ In prevalenza frammenti ceramici di sigillata italica, scarti di lavorazione del vetro, frammenti di laterizi e residui di intonaco dipinto.

${ }^{16} \mathrm{Al}$ I secolo d.C rimandano infatti i materiali ceramici rinvenuti nel livello più basso del riempimento, quando la funzione dell'impianto idrico venne meno $e$ nel condotto iniziarono ad accumularsi depositi di matrice limosa, di colore scuro, che ne riempirono progressivamente la cavità (Causarano 2005, p. 27; Cantini et al. 2006, p. 287).

${ }^{17}$ Sul rinvenimento, Cantini et al. 2006, p. 288; sull'argomento, Commella, Mele 2006. Siena era divenuta colonia militare con il nome di Saena Iulia forse intorno al 29 a.C.: per le ipotesi ricostruttive del reticolo urbano di epoca romana sulla collina del Duomo, si veda Pallecchi 2004-2005 e Pallecchi 2006.
} 

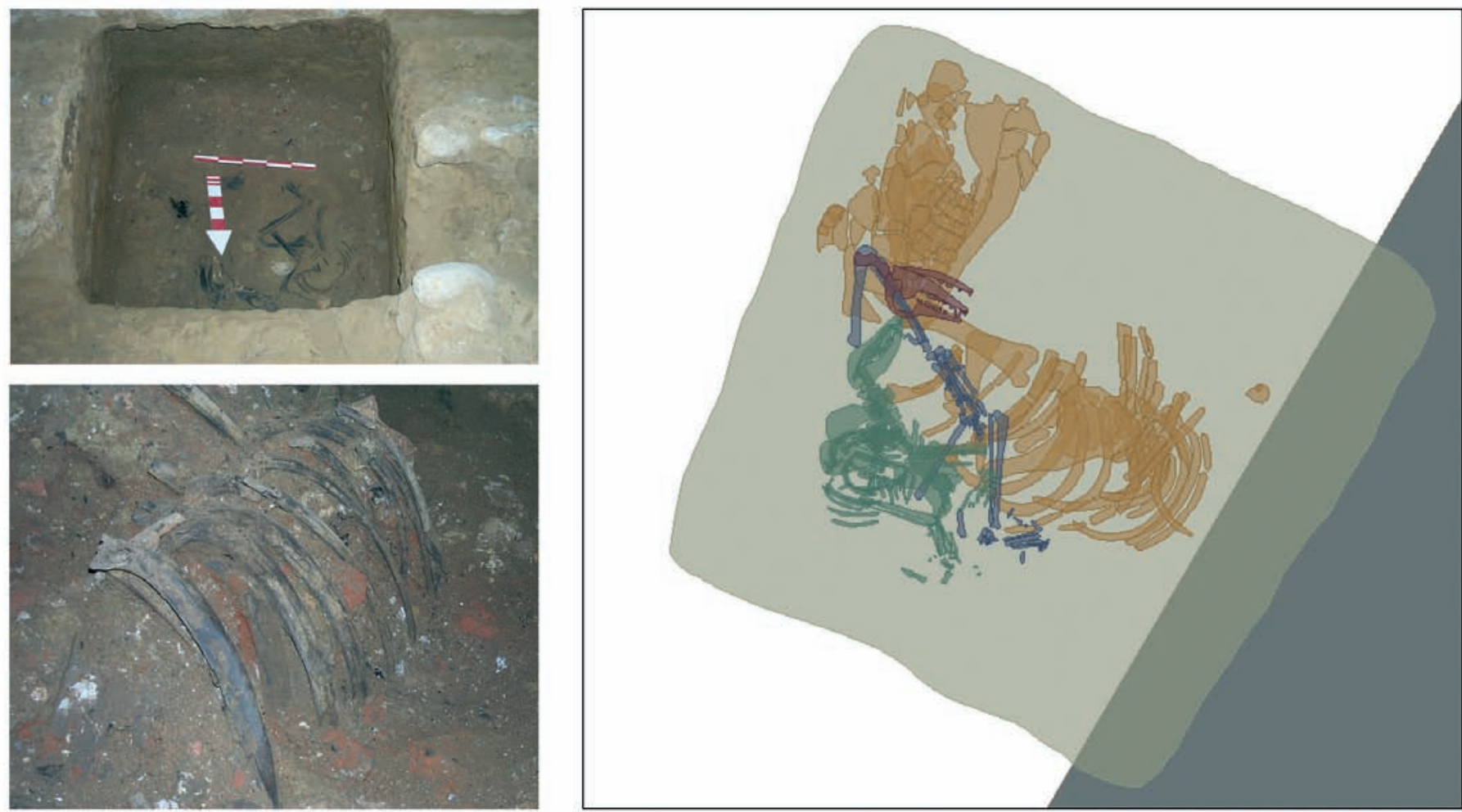

Fig. 8. A destra, il pozzetto votivo con i resti dei cani e del cavallo (piattaforma GIS della città di Siena). A sinistra, in alto particolare dei cani inumati; in basso, particolare della cassa toracica del cavallo

Età tardo antica - In età tardo antica, la parte ovest del versante occidentale continua ad essere interessata dallo scarico di materiali vari, provenienti forse anche da edifici di epoca romana ormai in disuso ${ }^{18}$, utilizzati ora a formare un piano omogeneo per regolarizzare il pendio della collina.

A breve distanza, infatti, dal limite del pianoro sommitale della collina (Ambiente $18^{19}$ ), è stata trovata parte di una struttura in pietra, conservata in fondazione e con andamento semicircolare, formata da pietre di calcare di grandi dimensioni non lavorate (Fig. 9). Intorno a questa struttura erano situate una serie di sepolture, scavate nelle sabbie plioceniche del colle, attribuibili ad una piccola area cimiteriale in uso tra età tardo antica e altomedioevo, situata al limite dell'abitato di epoca romana ormai in decadimento $^{20}$.

\footnotetext{
${ }^{18}$ Come sembra testimoniare la presenza di frammenti di intonaco dipinto e di mosaico a tessere bianche e nere.

${ }^{19}$ L'ambiente 18 è in realtà uno scannafosso realizzato allo scopo di isolare dall'umidità di risalita la parete sud-ovest dell'ambiente affrescato.

${ }^{20} \mathrm{La}$ presenza di una struttura in muratura di grandi dimensioni, molto probabilmente ancora in uso in età tardo antica, con annessa necropoli, può forse fare ipotizzare già in questo periodo l'esistenza di un'area religiosa, al momento però difficilmente interpretabile vista la mancanza di dati a nostra disposizione. Tra fine $X$ ed inizio XI secolo infine, sulla muratura rasata della struttura semicircolare si andò ad impostare, riutilizzandola come fondazione, l'abside della chiesa antecedente la cattedrale di epoca romanica, si veda infra, 2.2.
}

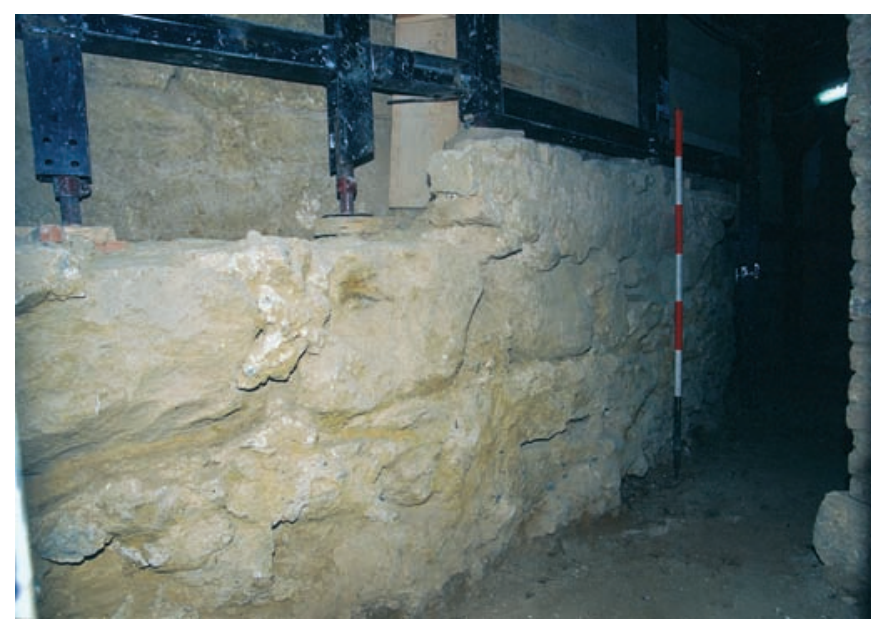

Fig. 9. La struttura con andamento semicircolare

Alto Medioevo (secc. VI-VII) - Tra VI e VII secolo il pendio settentrionale, ormai livellato, ospita una capanna semiscavata (Grubenhaus) con alzati in terra e canniccio: in un grande taglio circolare $(3,50 \mathrm{~m}$ di diametro e $2 \mathrm{~m}$ di profondità) era forse alloggiato il magazzino, mentre un assito ligneo poggiante su un piano d'appoggio ricavato nel terreno, una cornice circolare larga circa $50 \mathrm{~cm}$, doveva formare il pavimento (Fig. 10) ${ }^{21}$. La grubenhaus è databile,

${ }^{21}$ Sulla presenza di grubenhaus in Toscana tra fine VI e VII secolo, si veda Valenti 2004, pp. 22, 72-73. 

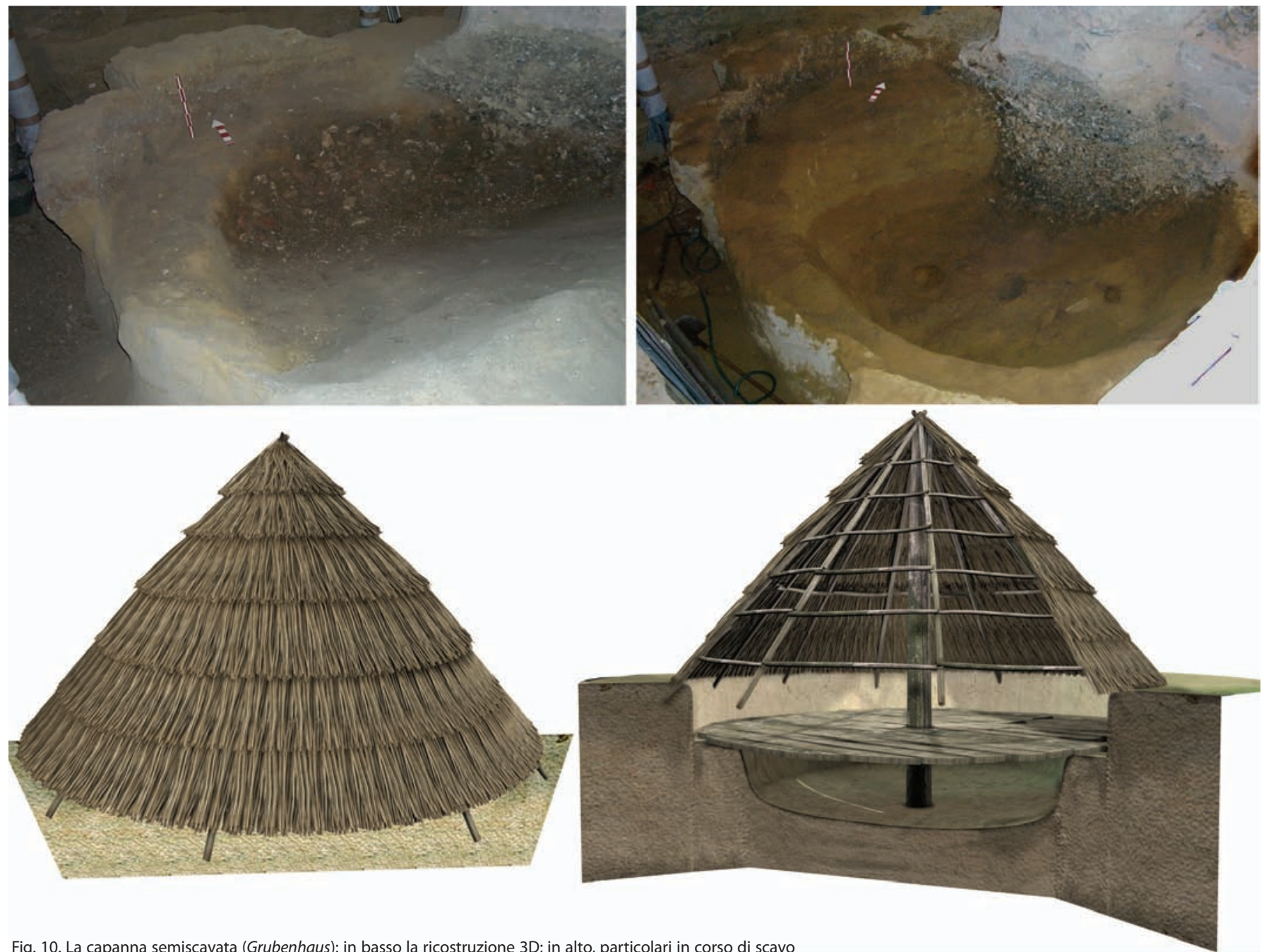

Fig. 10. La capanna semiscavata (Grubenhaus): in basso la ricostruzione 3D; in alto, particolari in corso di scavo

in base ai materiali ceramici rinvenuti, tra la fine del VI e l'inizio del VII secolo. Alla stessa epoca è riferibile una piccola area cimiteriale situata a pochi metri di distanza, composta da quattro sepolture in fossa terragna.

Secoli centrali del Medioevo (XI-XII secolo) - Nel corso del XII secolo la costruzione del transetto e del coro della cattedrale provocò profonde trasformazioni lungo le pendici nord-occidentali del colle. In particolare, i numerosi interventi cui fu soggetto il coro (Ambiente 1) causarono, sul versante nord, l'asportazione di gran parte della stratigrafia di epoca precedente ${ }^{22}$.

Inoltre, durante la prima metà del Trecento, le opere di ampliamento alla parte absidale della cattedrale portaro-

${ }^{22}$ Lo scavo ha infatti evidenziato la presenza, immediatamente sotto al piano pavimentale dell'ambiente affrescato di fine XIII secolo, di stratigrafie riferibili al VI-VII secolo, parzialmente asportate - come tutto il deposito stratigrafico di epoca successiva - durante l'edificazione e le opere di ampliamento della cattedrale. Si veda infra, 2.2. no ad una radicale trasformazione del versante occidentale del colle, con la conseguente perdita della maggior parte del deposito stratigrafico in posto: solo in un ambiente (Ambiente 7) sono stati rinvenuti resti di strutture riferibili ai secoli centrali del Medioevo (XI-XII secolo), precedenti l'edificazione della cattedrale di epoca romanica. Si tratta di alcuni annessi di servizio, due silos e due cantine, scavati nel tufo; i silos, di forma circolare, si sono conservati con una profondità di oltre 4 metri ed erano destinati alla conservazione delle granaglie (Causarano 2005, pp. 28-29).

\section{IL CANTIERE DELLA CATTEDRALE}

Assumere il cantiere della cattedrale di Siena e l'evoluzione del complesso architettonico tra XII e XIV secolo ${ }^{23}$ come

23 Già dalla fine dell'Ottocento il Duomo di Siena fu oggetto di studi approfonditi. Accanto al panorama documentario -edito da G. Milanesi a metà Ottocento (Milanesi 1854-1856), approfondito un secolo dopo da P. Bacci (Bacci 1944) e ampliato di recente da S. Moscadelli (Moscadelli 1995) - tra le 
elemento centrale della ricerca, porta inevitabilmente ad un confronto con problematiche storiografiche di portata generale. Il cantiere, in quanto luogo di produzione dove si concentrano tutta una serie di attività regolate da una propria organizzazione interna, comporta ricadute economiche e tecnologiche, legate all'uso dei saperi tecnici ed artistici, nella società medievale ${ }^{24}$.

Tale scelta prevede quindi una contestualizzazione della vicenda edificativa tanto sul piano urbanistico quanto sulle interazioni che vengono a costituirsi tra il cantiere stesso, la città ed il territorio circostante. In questa prospettiva, la cattedrale può essere definita, sotto certi aspetti, come il prodotto dell'ambiente fisico che la circonda.

\subsection{I materiali}

In epoca medievale l'approvvigionamento dei materiali da costruzione è nella maggioranza dei casi strettamente dipendente dalla loro disponibilità in loco: l'utilizzazione del materiale è poi correlata alle maestranze in grado di lavorarli e alle scelte dei committenti (Parenti 1995a, p. 374).

I materiali impiegati nel cantiere della cattedrale tra XII e XIV secolo non fanno eccezione e sono gli stessi utilizzati nelle architetture medievali a Siena e nel suo territorio (Fig. 11).

Nel cantiere della cattedrale senese ${ }^{25}$ pochi materiali hanno conosciuto un impiego paragonabile - per ampiezza e durata - a quello dei materiali lapidei e, in particolare, ai marmi impiegati fin dai primi decenni del Duecento, oltre che negli ornati, nel rivestimento dei paramenti murari esterni. Il loro costante approvvigionamento era garantito dall'Opera di Santa Maria che, fin dal XIII secolo, aveva preso in affitto e successivamente acquistato numerose cave di marmo bianco, un calcare di tipo cristallino, nella Montagnola Senese ${ }^{26}$; dalla zona del Vescovado, in particolare dal territorio di Murlo e Crevole, proveniva

numerose opere dedicate alla cattedrale, la corposa monografia di V. Lusini, gli studi di E. Carli, le indagini di C. Pietramellara e le ricerche di A. Midderdolf Kosegarten risultano ancora oggi imprescindibili per la definizione storicoarchitettonica del monumento (Lusini 1911-39; Carli 1979; Pietramellara 1980; Midderdolf Kosegarten 1988).

${ }^{24}$ Sul ruolo del cantiere della cattedrale nella società urbana basso-medievale e la progressiva definizione istituzionale di tale cantiere, sull'organizzazione e le condizioni di vita delle maestranze, si veda Giorgi, Moscadelli 2005, pp. 15-18 a cui si rimanda anche per la vasta bibliografia di riferimento.

25 Sulle modalità di approvvigionamento dei materiali da costruzione per il Duomo da parte dell'Opera, si veda Giorgi, Moscadelli 2005, pp. 193-229.

${ }^{26}$ La grande diffusione del marmo proveniente dalla Montagnola è testimoniato, oltre che dal vasto utilizzo nel Duomo di Siena, anche dal suo impiego nella costruzione della cattedrale di Santa Maria del Fiore a Firenze alla metà del Trecento (Sartori 2002, p. 39) e nella facciata del duomo di Orvieto, a partire dal 1321 (Parenti 1995b, p. 104)

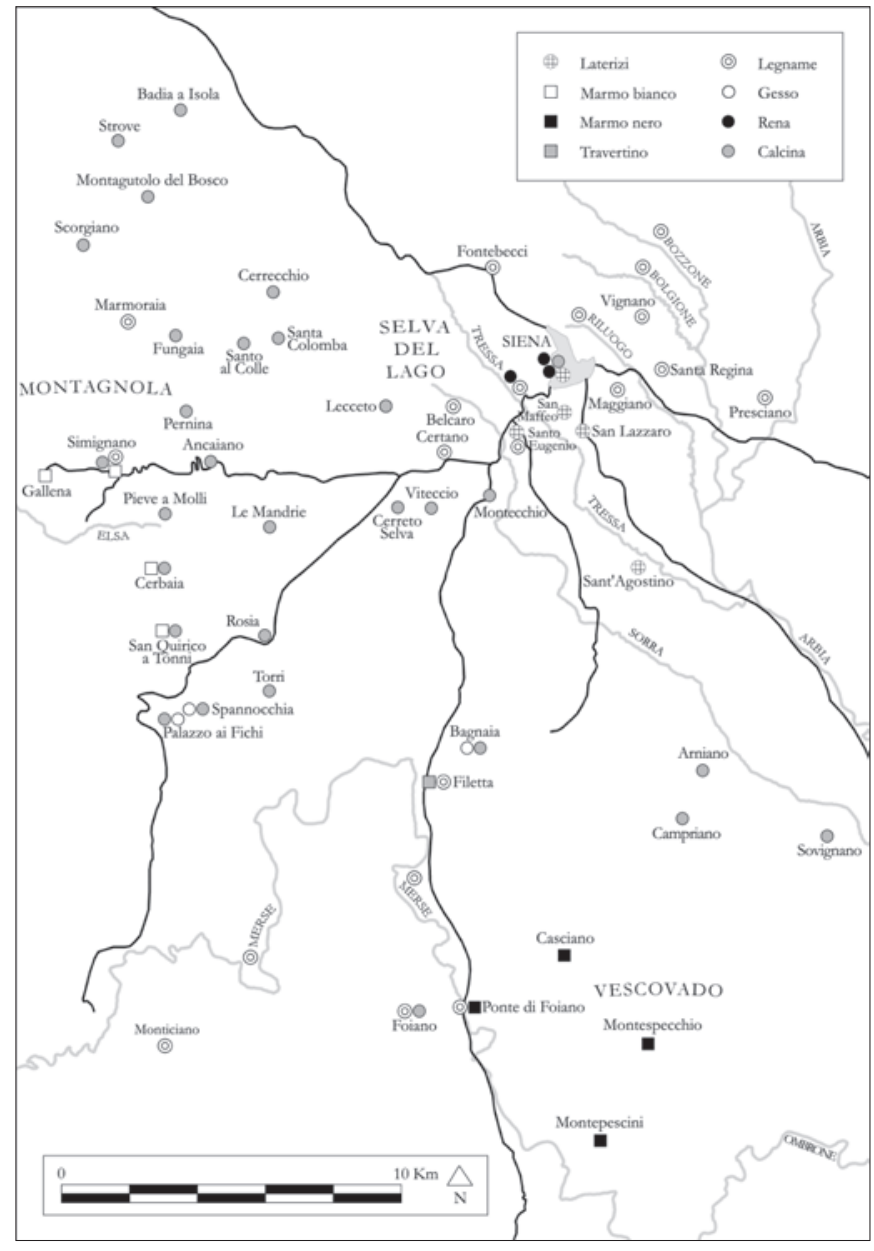

Fig. 11. Luoghi di provenienza dei materiali (da Giorgi, Moscadelli 2005, tav. X)

invece il cosiddetto "marmo nero», una serpentina di colore verde scuro ${ }^{27}$. Quest'ultima è una roccia con tipica struttura 'a maglie' e con un'ampia gamma cromatica, che va dal nero al blu con riflessi che degradano fino alle diverse tonalità del verde, facilmente alterabile.

Tra i materiali litici impiegati nel Duomo si distinguono inoltre il calcare cavernoso ed il travertino, impiegati specialmente nelle fasi edilizie databili tra XI e inizio XIII secolo.

Il calcare retico, detto "calcare cavernoso", ha un aspetto brecciforme con superficie tipicamente spugnosa, di colore grigio chiaro e scuro. Il termine "cavernoso" si riferisce alla forte porosità di questa roccia, ricca di vuoti lasciati dalla dissoluzione del deposito originario. Questo calcare era noto in passato come "pietra da torre» e si trova

${ }^{27}$ Il litotipo nero è anch'esso frequente nei paramenti dei grandi monumenti religiosi: a Pisa è presente con i calcari neri dei Monti Pisani, a Firenze, Pistoia e Prato con la serpentina di Prato, a Carrara con il "Nero di colonnato», a Siena con la serpentina di Vallerano di Murlo e di Crevole (Sortori 2002, p. 60; Rodolico 1964 , p. 288). 
nell'area della Montagnola Senese; insieme all'arenaria pliocenica è il litotipo più comune usato negli edifici medievali di Siena.

Con il termine «travertino» si indicano invece vari tipi di rocce carbonatiche, provenienti dal territorio senese e dall'Alta Valdelsa: facile al taglio in cava, la durezza di questa roccia cresce dopo l'estrazione, con l'esposizione all'aria, mentre appena estratta è facilmente lavorabile. Tali proprietà, insieme alle ottime doti di resistenza meccanica e alla mancanza di gelività, spiegano la notevole diffusione del travertino senese.

Ampiamente utilizzati nella cattedrale sono poi $\mathrm{i}$ laterizi ${ }^{28}$ mentre l'approvvigionamento di materiali quali la calce (calcina), il gesso o la sabbia (rena) e, in generale tutte le componenti utili alla preparazione della malta, era garantito da cave poste in genere tra la Montagnola Senese, la Selva del Lago e la città.

Il legname - principalmente castagno, pioppo e olmo - fu largamente impiegato nella carpenteria per l'allestimento di ponteggi e centinature oltre che nelle opere con funzione strutturale e di copertura: proveniva dalle immediate vicinanze della città, con un areale di approvvigionamento che in genere rimaneva compreso in un raggio di non più di $3 \mathrm{~km}^{29}$.

\subsection{L'evoluzione della cattedrale}

I dati provenienti dall'analisi diretta dell'architettura e dei suoi materiali, insieme ai risultati delle indagini di scavo, hanno permesso di individuare le principali fasi costruttive dell'area absidale della cattedrale, con un arco cronologico che va dall'XI secolo alla prima metà del XVIII secolo (Causarano et al. 2003, pp. 159-164; Causarano 2005, pp. 29-34) (Fig. 12). Per l'evoluzione dell'intero complesso architettonico $^{30} \mathrm{e}$, in particolare, delle trasformazioni subite dal corpo centrale del Duomo tra la seconda metà del XIII secolo e la metà del XIV secolo, gli studi condotti dall'équipe del progetto Die Kirchen von Siena, promosso dall'Istituto Germanico di Storia dell'Arte di Firenze (Istituto Max Planck), sono stati un punto di riferimento

${ }^{28}$ Nonostante il loro impiego nel cantiere del Duomo sia attestato in murature databili già tra la fine del XII ed i primi anni del XIII secolo, non si dispone di documentazione scritta sistematica relativa al loro acquisto prima del 1270, quando l'Opera acquista una fornace situata a San Maffeo, nelle vicinanze della città (Giorgi, Moscadelli 2005, p. 193). L'uso del mattone nell'edilizia senese è preponderante a partire dal XIII secolo: sull'argomento si vedano, nella vasta bibliografia, Balestraci, Piccini 1977, p. 63 e ss.; Bianchi 1991, p. 12; Parenti 1995a, pp. 384-388; Gabbrielli 1995, Gabbrielli 2003, pp. 29-41.

${ }^{29}$ L'attenzione riservata dal Comune di Siena alle zone di approvvigionamento di legname grezzo è testimoniata, tra l'altro, nel XIII secolo, dalle ordinanze che regolano l'amministrazione della Selva del Lago (Redon 2008, pp. 5-56).

${ }^{30}$ Cfr. nota 23. imprescindibile: le ricerche di Monica Butzek per la cronologia (Butzek 2006), di Andrea Giorgi e Stefano Moscadelli per il cantiere (Giorgi, Moscadelli 2005), di Walter Haas e Dethard von Winterfeld per l'analisi architettonica (Haas, Winterfeld 2006), hanno permesso inoltre di definire con maggiore precisione le fasi di edificazione della facciata occidentale del Duomo e delle navate (Causarano 2009).

Grazie ai recenti lavori di restauro condotti dall'Opera Metropolitana di Siena è stato inoltre possibile studiare e classificare le murature, analizzando nel dettaglio il rapporto stratigrafico tra i diversi corpi di fabbrica e, in particolare, le tracce relative alle modalità costruttive adottate dai cantieri succedutisi nell'ampliamento del corpo basilicale.

Per le tecniche di lavorazione e posa in opera del materiale da costruzione impiegato e, più in generale, per comprendere l'organizzazione delle maestranze all'opera nei diversi cantieri, si è proceduto inizialmente all'individuazione dei principali «nodi stratigrafici», al fine di collegare le fasi di sviluppo nelle murature oggetto di indagine sia ad una più generale e ben nota sequenza evolutiva dell'intero complesso architettonico, sia allo studio approfondito delle murature ad essi pertinenti. Alla lettura stratigrafica, è seguita poi l'analisi ed il campionamento dei diversi paramenti murari individuati nel corso della ricerca, allo scopo di individuare le principali tipologie costruttive e intraprendere l'analisi mensiocronologica delle murature in laterizio del XIII e XIV secolo e del materiale lapideo impiegato nel Duomo tra XII e prima metà XIV secolo ${ }^{31}$.

Ante XII secolo - Della realtà urbanistica anteriore al XII secolo, incentrata sulla più antica cattedrale e sul complesso canonicale, si è persa quasi completamente traccia e poche sono le attestazioni documentarie (Giorgi, Moscadelli 2005, pp. 49-54). Tra IX e X secolo si ha menzione dell'esistenza di edifici episcopali e canonicali, di incerta ubicazione $^{32}$; risale invece al 1012 la prima sicura localizzazione della domus episcopio Senense e del relativo castello ${ }^{33}$

\footnotetext{
${ }^{31}$ Si veda infra, Appendice. A questo scopo sono stati isolati i dati statisticamente significativi, relativi in genere alla variabile della lunghezza e dello spessore per i laterizi, dell'altezza per il materiale lapideo (calcare cavernoso, marmo e serpentino). Infine, lo studio delle tracce di lavorazione, effettuato tramite "frottage», ha permesso di individuare gli strumenti impiegati dagli scalpellini e le modalità del loro utilizzo.

${ }^{32}$ E' attestata dai documenti una domus Senate ecclaesie nel 833, una domus episcopii nel 881, una sedis Beate Mariae nel 913 e si ha notizia di una canonica Sancte Marie domus episcopio Senese nell'aprile dell'anno 1000 (Giorgi, Moscadelli 2005, p. 49).

33 La denominazione del complesso della cattedrale di Santa Maria come castellum (castello Sancte Marie domus episcopio Senense) è documentata con regolarità per tutto l'XI secolo.
} 
Fig. 12. L'evoluzione della parte posteriore della cattedrale (piattaforma GIS della città di Siena). In alto a sinistra, in evidenza le aree oggetto ad analisi degli elevati

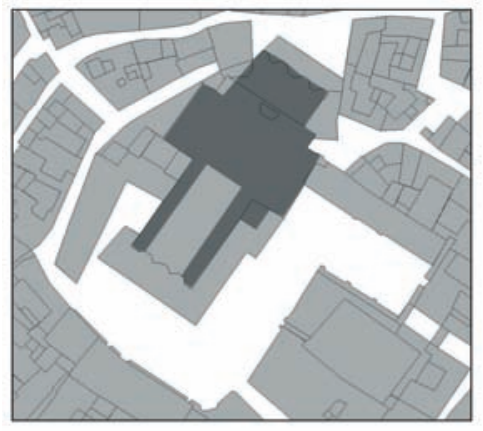

\section{a.}

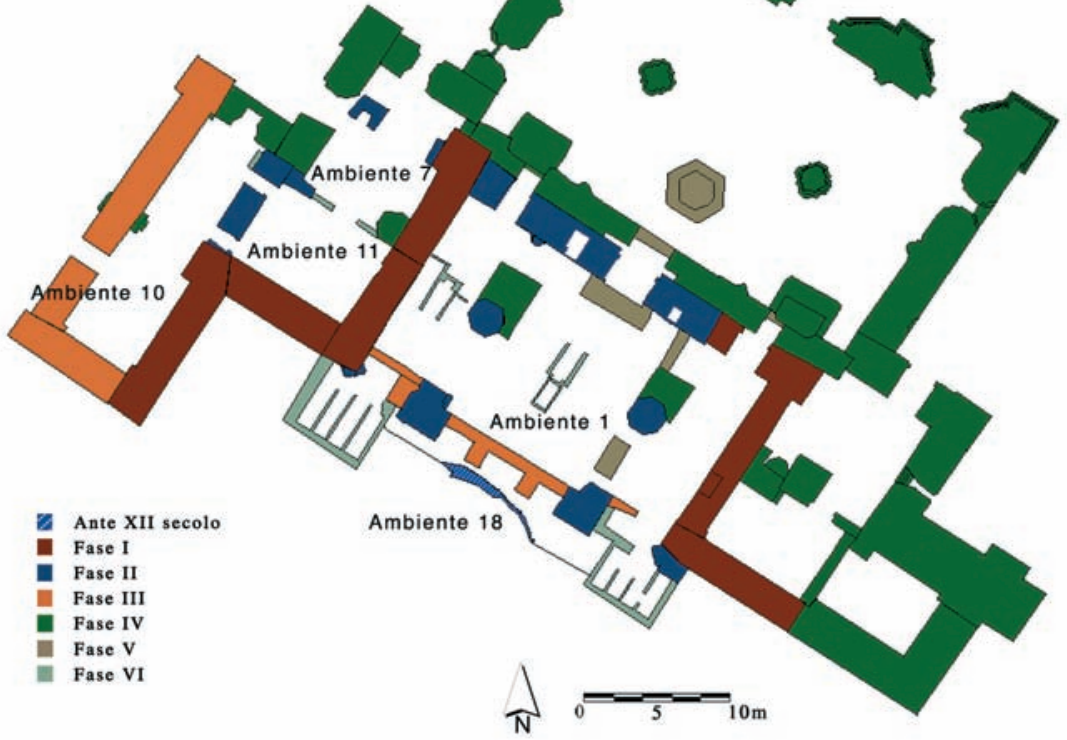

nell'area sovrastante la chiesa di San Desiderio. Tra le strutture facenti parte del complesso della cattedrale nel 1105 è attestato un gardingo de episcopio e, già nel 10741075 ma con più regolarità a partire dal terzo decennio del XII secolo, si fa riferimento all'esistenza di un palatium episcopi. Risalgono invece agli anni Settanta e Ottanta dell'xi secolo le prime indicazioni relative con certezza all'edificio della canonica e ai suoi annessi (claustrum, refectorium). Il complesso della cattedrale si presenta dunque in questo periodo come una cittadella polifunzionale fortificata (castellum), una «articolata cittadella di tipo monasteriale» (Brogini 1991-1992, p. 248).

Può essere ascrivibile alla chiesa di XI secolo il paramento murario curvilineo, verosimilmente absidale, rinvenuto durante lo scavo del vano sottostante la cupola (Ambiente 18) e identificabile forse con la tribuna de ecclesia Sancte Marie Senensis episcopio attestata nel 1076 (Giorgi, Moscadelli 2005, p. 50).

L'abside si imposta sulla rasatura della struttura curvilinea di età imperiale, che riutilizza come fondazione anche se con un diametro inferiore (Fig. 13). E' realizzata in pietra calcarea, lavorata in blocchi sbozzati di dimensioni piuttosto variabili posti in opera su filari sub-orizzontali e tendenzialmente paralleli. Conservata per soli tre filari di

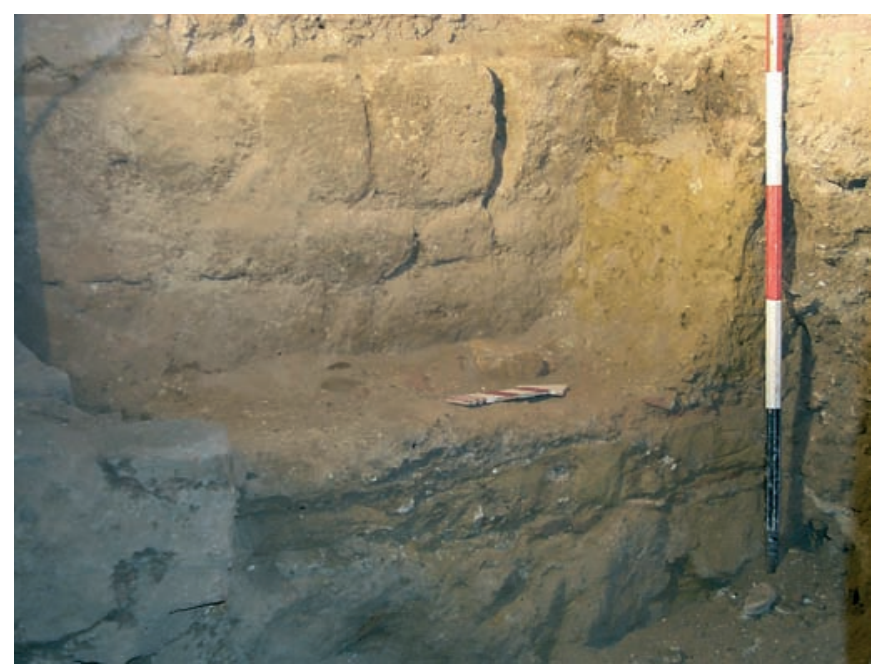

Fig. 13. Particolare dell'abside della chiesa di xı secolo 
alzato, non permette uno studio approfondito della tecnica costruttiva: si nota comunque la tendenza ad una progressiva regolarizzazione nella posa in opera dei filari e l'impiego di uno strumento a punta per la realizzazione della spianatura superficiale dei blocchi del filare superiore (Tipo 9).

Se identifichiamo questa muratura come l'abside, nonché l'unica struttura supersite, della cattedrale di XI secolo, possiamo notare che l'edificio ha mantenuto nel corso dei secoli lo stesso orientamento e lo stesso asse, ampliandosi progressivamente verso nord/nord-est.

La struttura perse di funzione con l'ampliamento della cattedrale nel XII secolo e, in seguito, fu quasi completamente rasata al momento della costruzione della cupola, negli anni '60 del XIII secolo.

Fase I (XII secolo) - Nel periodo che va dai primi decenni del XII secolo all'inizio del Duecento si verificano trasformazioni decisive nell'assetto urbanistico dell'area circostante la cattedrale e nella cattedrale stessa.

Tutta la parte orientale del Duomo fu soggetta ad una radicale trasformazione: da chiesa con terminazione absidale a chiesa a croce latina ${ }^{34}$. Nel corso del XII secolo si realizzarono infatti una serie di interventi che portarono alla creazione di un ampio transetto e di un coro rettilineo, collegato a un ambiente sottostante dotato di ingressi orientali posti ad un livello altimetrico inferiore rispetto al piano di calpestio della cattedrale stessa. L'esigenza di un collegamento diretto tra la cattedrale e la città è motivato dalla particolare conformazione della collina del Duomo: il forte dislivello presente tra il pianoro superiore e il versante nord-occidentale, a picco su aree urbane di recente sviluppo quali San Pellegrino e Vallepiatta, motiva l'edificazione di un ambiente sottostante il coro, con funzione di sostruzione, e la costruzione di una facciata posteriore ${ }^{35}$.

Si ha inoltre notizia della presenza di una confessio, oggi non conservata ${ }^{36}$.

\footnotetext{
${ }^{34}$ Le trasformazioni subite dal corpo basilicale della chiesa tra XI e XII secolo non sono oggi interamente leggibili. Con l'eccezione degli ambienti sottostanti il coro ed il transetto - dove si sono conservate integralmente le murature testimonianti le diverse fasi costruttive e gli ampliamenti subiti dalla cattedrale nella sua parte settentrionale - le uniche altre parti del Duomo dove si conservano strutture precedenti alla seconda metà del XIII secolo sono il sottotetto della navata laterale destra e l'interno del campanile.

${ }^{35}$ Di una facciata orientale, di cui si era persa memoria, fanno menzione le fonti scritte che attestano l'esistenza di ingressi su questo lato della cattedrale già nel 1177-1180. Sull'accesso orientale al Duomo, rimasto in uso fino alle trasformazioni trecentesche, si veda Giorgi, Moscadelli 2005, pp. 56-57.

${ }^{36}$ Notizie sull'esistenza di una confessio sottostante la cattedrale si ricavano dai riferimenti presenti nell'Ordo officiorum di inizio Duecento e dalla documentazione posteriore alla metà del secolo (sull'argomento, si veda Argenziano 2000; Giorgi, Moscadelli 2005, p. 63 con i relativi riferimenti bibliografici).
}

Il campanile, a pianta quadrata, era situato nell'angolo esterno tra transetto e corpo basilicale. Non si conserva l'accesso originario alla struttura ma l'interno conserva ancora l'originario paramento in conci squadrati, con periodiche aperture circolari (oculi) delimitate da un archivolto in pietra: l'analisi degli elementi architettonici e della tecnica costruttiva (Tipo 1) confermano che la costruzione del campanile è attribuibile alla stessa fase edilizia che vide la trasformazione a croce latina dell'intera parte absidale ${ }^{37}$.

Le murature caratterizzanti questa fase sono infatti realizzate tutte in conci di calcare cavernoso, la locale "pietra da torre», squadrati e sommariamente spianati nella faccia a vista con uno strumento a lama (probabilmente un ascettino), posti in opera su filari orizzontali e paralleli (Fig. 14). Le misurazioni eseguite, mirate ad uno studio mensiocronologico del materiale lapideo impiegato dal cantiere, mostrano l'utilizzo di conci con altezze costanti raggruppabili in due gruppi di misure principali comprese tra i $19-22 \mathrm{~cm}$ ed i $20-23 \mathrm{~cm}$, a conferma di un'attenta selezione operata sul materiale da utilizzare nel cantiere ${ }^{38}$.

Fase II (inizio XIII secolo-1263) - A questa fase vanno riferiti gli interventi attestati dai documenti già nei primi decenni del XIII secolo ${ }^{39}$ e terminati con la costruzione della cupola nel 1263, che videro un ulteriore ampliamento dell'ecclesia maior del XII secolo.

Tutta la parte orientale della chiesa edificata in conci di pietra nel corso del XII secolo fu sopraelevata e in parte ricostruita con murature in laterizi che, impostandosi sui muri perimetrali del coro e del transetto della chiesa precedente, ne ricalcarono sostanzialmente l'andamento. Ben visibili nei locali con accesso da via de' Fusari, le murature presentano una cesura nell'alzato posta a quote diverse nei singoli ambienti indagati e tra paramento interno ed esterno delle stesse murature.

Il locale sottostante il coro (Ambiente 1), dotato già a partire dagli ultimi decenni del XII secolo di una facciata rivolta ad oriente, fu in parte trasformato nei primi decenni del XIII secolo: le murature in pietra furono anche

\footnotetext{
${ }^{37}$ Le dimensioni e le murature realizzate in calcare cavernoso avevano fatto invece ipotizzare ad alcuni studiosi che il campanile fosse in origine una torre gentilizia riutilizzata poi nella cattedrale romanica come torre campanaria (sull'argomento, Tragbar 1995).

${ }^{38}$ Un'indagine condotta sulle murature in pietra degli edifici di epoca medievale del centro storico di Siena ha mostrato tre intervalli principali nei quali si collocano le altezze delle pietre: il più rappresentativo è compreso tra 21 e $28 \mathrm{~cm}$, mentre le varianti, tra $14-21 \mathrm{~cm}$ e $35-44 \mathrm{~cm}$, sono attribuibili in genere alla pratica del reimpiego (Cataldo 2003, p. 118).

${ }^{39}$ Le prime menzioni di operai si trovano nel più antico dei registri conservatisi dell'ufficio comunale della Biccherna, del 1227.
} 


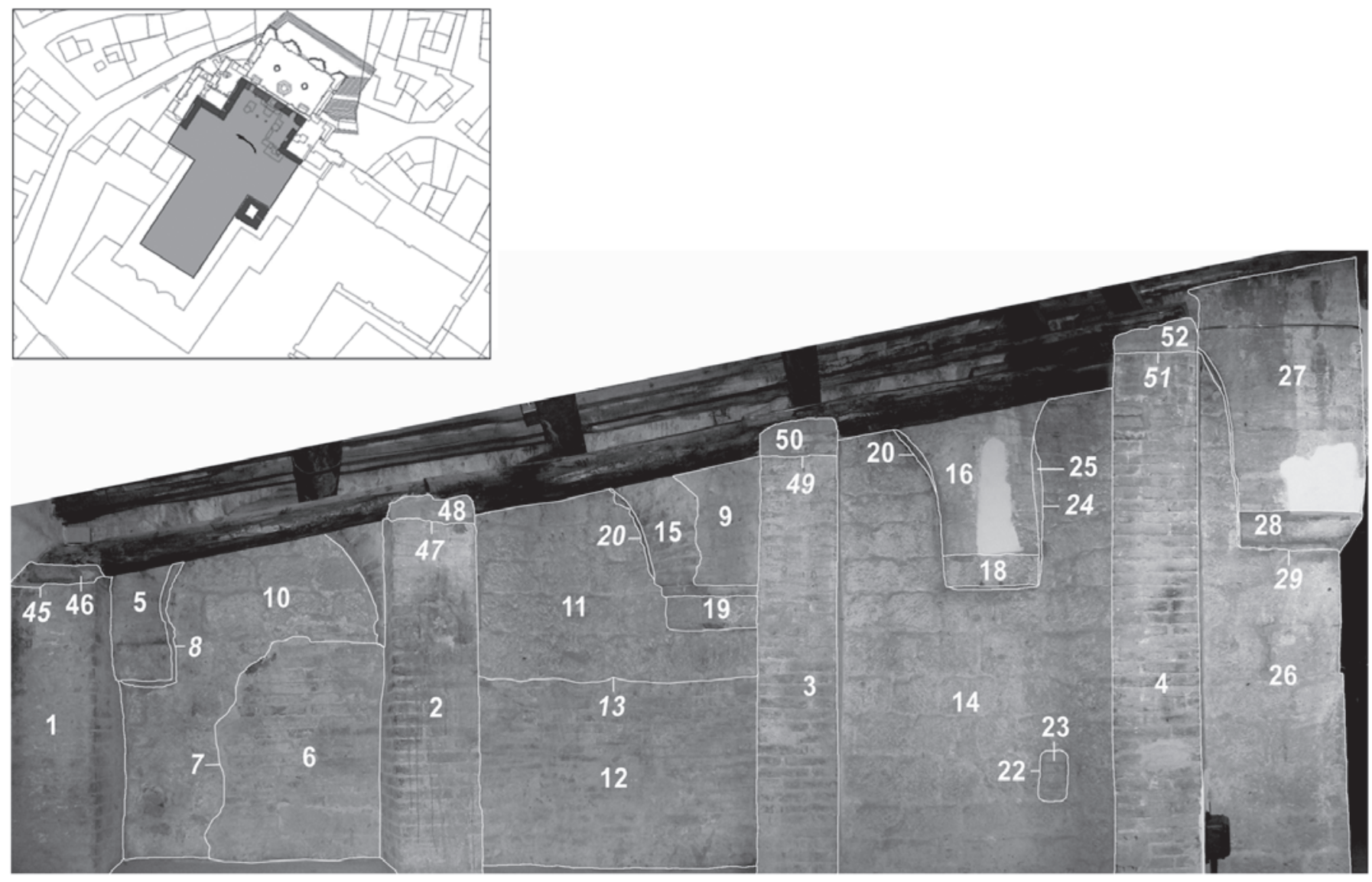

Fig. 14. Le murature di XII secolo: in alto, ipotesi sull'estensione del Duomo di XII secolo. In basso, fotomosaicatura con in evidenza le principali Unità Stratigrafiche Murarie della porzione di campanile visibile nel sottotetto della navata laterale sud-est: le USM 10, 11, 14 e 26 appartengono alla fase originaria del campanile, databile al XII secolo

in questo caso parzialmente ricostruite ${ }^{40}$ con un paramento in mattoni graffiati.

Le analisi condotte sui laterizi visibili nelle murature dell'ambiente affrescato, hanno evidenziato - nei tratti di muratura privi di pittura - l'impiego dello stesso tipo di mattoni su tre delle quattro pareti: la controfacciata ed i muri nord-ovest e nord-est. I laterizi, graffiati, sono diversi per dimensioni, tecnica e fattura da quelli impiegati nei prospetti esterni.

L'ottimo stato di conservazione ne ha consentito inoltre lo studio dimensionale e l'analisi mensiocronologica: i valori della lunghezza $(27,2 \mathrm{~cm})$ e della larghezza $(12$ $\mathrm{cm}$ ), non sono attestati tra le misure dei laterizi da costruzione impiegati a Siena a partire almeno dai decenni centrali del Duecento. L'accurata fattura, la realizzazione delle graffiature ed i valori dimensionali anomali, portano

40 Per quanto riguarda i muri perimetrali dell'Ambiente 1, la muratura in mattoni ha lo stesso ingombro della sottostante muratura in pietra. Unica eccezione è la parete nord-ovest dove, nel prospetto interno, si nota una riduzione di spessore di circa $25-30 \mathrm{~cm}$, corrispondente allo spazio del paramento lapideo. ad ipotizzare che si tratti di mattoni appositamente foggiati per il cantiere della cattedrale ${ }^{41}$.

I laterizi mostrano una finitura a graffiature oblique di norma parallele, realizzata prima della loro posa in opera, con uno strumento a lama piana, probabilmente un ascettino (Fig. 15). La direzione dei graffi è sempre la stessa, dall'alto verso il basso e da sinistra a destra, ma l'angolo di inclinazione e la distanza (da 1 a $5 \mathrm{~mm}$ ) varia da mattone a mattone (Gabbrielli 2003, pp. 29-31).

In questa fase le murature del vestibolo orientale della cattedrale, affrescate negli anni '80 del secolo, sono desti-

\footnotetext{
${ }^{41}$ La curva mensiocronologica realizzata alla fine degli anni ' 80 per la città di Siena da R. Corsi (Corsi 1988-1989) parte infatti con l'analisi della Fonte di Follonica, datata al 1248. Recenti indagini svolte durante uno scavo di emergenza in via Baroncelli, hanno portato alla luce un tratto di circuito murario in laterizi databile tra la fine del XII ed il secondo quarto del XIII secolo (Causarano, Tronti 2005): l'analisi mensiocronologica ha individuato laterizi con lunghezza media di $28,2 \mathrm{~cm}$ ed uno spessore medio pari a $5,4 \mathrm{~cm}$, misure simili a quelle attestate a Siena intorno ai decenni centrali del XIII secolo. Il divario dimensionale con i laterizi attestati nel Duomo di Siena tra gli ultimi anni del XII e l'inizio del XIII secolo porta ad ipotizzare per questi ultimi un'apposita realizzazione per il cantiere della cattedrale. Non disponiamo però di documentazione scritta sistematica relativa all'acquisto di laterizi da parte dell'Opera di Santa Maria prima del 1270 (cfr. nota 28)
} 


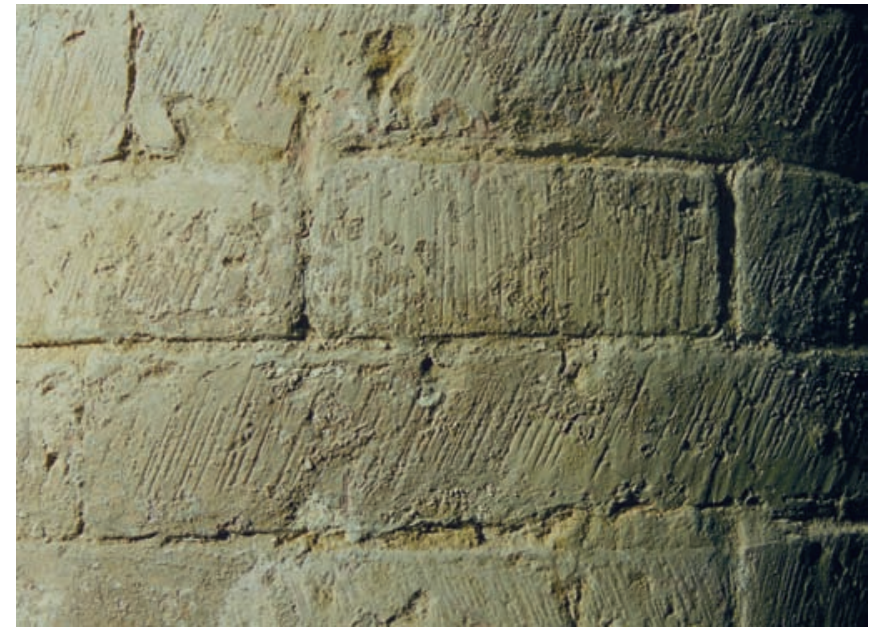

Fig. 15. Elemento architettonico in laterizi graffiati, particolare

nate a rimanere a vista: il trattamento dei laterizi riguarda, infatti, sia le superfici murarie che gli elementi architettonici e la cortina muraria diventa così essa stessa una decorazione.

La loro datazione è probabilmente collocabile all'inizio del XIII secolo ${ }^{42}$, in fase con la 'foderatura' in pietra del muro di facciata, realizzata in conci di calcare perfettamente squadrati con l'uso del nastrino (Fig. 16) e spianati con uno strumento a lama dentata, verosimilmente una martellina dentata a punte fini (tipo 8$)^{43}$. I portali vengono decorati con stipiti, anch'essi in pietra, terminanti con semicapitelli decorati a fogliame ${ }^{44}$.

Si conservano ancora alcuni degli elementi architettonici che scandivano lo spazio interno all'ambiente: oltre ai due grandi pilastri ottagonali del coro, due semicolonne addossate alla parete di controfacciata e un peduccio a cono rovesciato erano funzionali al sostegno del sistema di copertura dell'ambiente, mentre due pilastri cruciformi realizzati anch'essi con laterizi graffiati - erano situati al passaggio tra coro e transetto.

L'ampliamento della cattedrale nella sua parte absidale è testimoniato in questa fase dalla costruzione di un ambiente esterno, posto tra coro e braccio sinistro del transetto (Ambiente 11). Il corpo di fabbrica, interamente

${ }^{42}$ Laterizi con graffiature simili sono attestati nelle murature di fine XII secolo della «rotonda» di San Galgano a Monte Siepi (Gabbrielli 2003, p. 43).

${ }_{43}$ Attualmente della facciata duecentesca è visibile solo una porzione limitata, conservatasi esternamente al portale centrale nel punto dove l'abside quattrocentesca del Battistero ha in parte asportato le murature più antiche. Questo tipo di muratura (Tipo 8) trova riscontro nelle murature dell'abbazia di San Galgano, eretta a partire dagli anni '20 del XIII secolo.

${ }^{44}$ Nel Duecento i tre portali venivano comunemente chiamati: maior ianua quello centrale, ianua versus domum Guidi Troiani quello laterale meridionale e ianua versus pontem quello settentrionale, probabilmente rivolto verso l'odierna via di Diacceto (Giorgi, Moscadelli 2005, p. 57). costruito in laterizi, era formato da due campate coperte in origine con volte a crociera - delle quali si conserva ancora la partenza delle imposte - che davano luce, tramite due aperture fortemente strombate, ad un ambiente inferiore (Ambiente 7).

Fase III (1263 circa - inizio XIV secolo) - Nei decenni centrali del XIII secolo si manifestarono, con l'arrivo a Siena di Nicola Pisano ${ }^{45}$, rilevanti cambiamenti nella composizione delle maestranze impegnate nel cantiere mentre, sul piano gestionale, fu avviata una stretta collaborazione con l'abbazia di San Galgano ${ }^{46}$, prima con l'operariato di frate Vernaccio - primo converso cistercense a ricoprire questa carica - poi con frate Melano di Rinaldo, operaio della cattedrale dal 1259.

In questi anni si va delineando inoltre un progetto di ampliamento complessivo della cattedrale che vedrà, sotto il cantiere di Nicola Pisano, la costruzione della cupola, il rifacimento del coro e dell'ambiente sottostante e l'ampliamento del corpo basilicale con il conseguente inserimento del campanile, prima esterno all'edificio religioso, nel corpo della chiesa ${ }^{47}$. I lavori proseguiranno fino all'inizio del Trecento sotto Giovanni Pisano, con l'ampliamento di una campata del corpo basilicale e la costruzione della nuova facciata occidentale ${ }^{48}$.

Le murature visibili nei sottotetti delle navate laterali permettono di studiare ciò che resta del paramento marmoreo conservatosi del corpo basilicale duecentesco, terminato prima del 1284 quando si iniziò la costruzione della nuova facciata e dell'ulteriore campata (Causarano 2009).

La navata centrale era rivestita, come la cupola, a fasce alterne di filari di marmo bianco e «marmo nero» posti in

\footnotetext{
${ }^{45} \mathrm{La}$ prima attestazione documentaria che testimonia la presenza a Siena di Nicola Pisano è dell'aprile 1259 (Carli 1979, pp. 17-18; Giorgi, Moscadelli 2005, p. 72).

${ }^{46}$ La questione dei rapporti tra l'Opera di Santa Maria e l'abbazia cistercense di San Galgano è tradizionalmente presente negli studi riguardanti l'edificazione della cattedrale senese (si vedano Carli 1979, Bagnoli 1981 e i recenti studi in Garzelli 2000 e Gabbrielli 2003). Negli ultimi anni si è posta attenzione anche alla dimensione storico-culturale e istituzionale nei rapporti tra $\mathrm{i}$ due enti (Giorgi, Moscadelli 2001; Giorgi, Moscadelli 2002).

${ }^{47}$ Sul cantiere di Nicola Pisano all'opera nella cattedrale di Siena e sulla paternità nicoliana del ciclo scultoreo della cupola si vedano, nella vasta bibliografia: Carli 1979, pp, 17 e ss; Pietramellara 1980, pp. 35-43; Bagnoli 1981, Bagnoli 2003. Sulle caratteristiche e le finalità dei lavori condotti dopo la metà del Duecento nella cattedrale, nella porzione della platea episcopatus situata nell'area retrostante il Duomo e, più in generale, sulla sistemazione urbanistica del Planum Sancte Marie, cfr. Giorgi, Moscadelli 2005, pp. 71-78.

${ }^{48}$ Sul cantiere di Giovanni Pisano ed i lavori alla facciata occidentale, si vedano i recenti studi in Quast 2007 e Haas, von Winterfeld 2006, pp. 439-450; sui lavori condotti nella cattedrale tra fine Duecento ed inizio Trecento si vedano, Carli 1979, p. 19; Giorgi, Moscadelli 2005, pp. 78-81.
} 

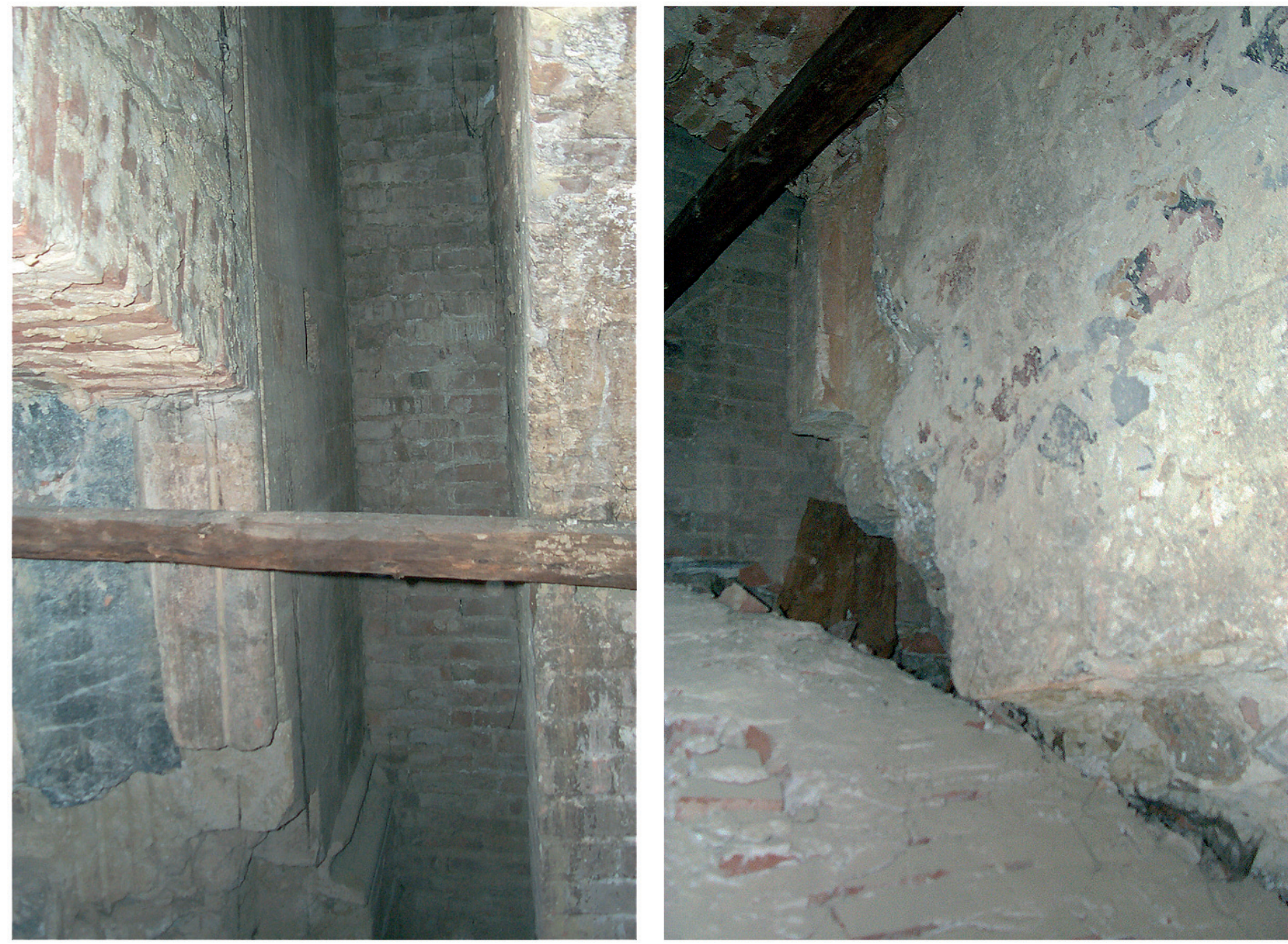

Fig. 16. Particolari della facciata orientale della cattedrale: a sinistra, particolare del paramento murario esterno della facciata e dello stipite destro del portale centrale; a destra, particolare dello stipite sinistro del portale centrale, tagliato dall'abside del Battistero

opera su corsi perfettamente orizzontali e paralleli, squadrati con l'uso del nastrino e perfettamente spianati con l'impiego della martellina dentata a punte fini.

I fianchi della navata erano scanditi da un sistema di archetti pensili, in marmo, con una luce costante di circa 2 $\mathrm{m}$. Le arcatelle erano sorrette da peducci decorati, anch'essi in marmo, e si dovevano trovare in origine immediatamente sotto la linea di gronda del tetto della navata maggiore; tra queste si aprivano presumibilmente le finestre più antiche, di cui oggi non resta traccia perché asportate al momento dell'apertura delle grandi trifore trecentesche costruite insieme alla sopraelevazione della navata (Fig. 17).

Nel 1284, dopo la demolizione della vecchia facciata della cattedrale e del presunto portico attestato dai documenti (Quast 2007, pp. 105-106), con la posa in opera della prima pietra per la costruzione della nuova facciata si dette avvio ad un'ulteriore prolungamento delle navate, dell'ampiezza di una campata.
Le notevoli modifiche apportate, nel terzo quarto del XIII secolo, alla porzione orientale del Duomo con la costruzione dell'esagono sormontato da una cupola $^{49}$, e la realizzazione, negli anni seguenti, dell'arredo del coro liturgico, comportarono la trasformazione della cosiddetta 'cripta', il vano di sostruzione al coro.

Terminata, all'inizio degli anni '60 del Duecento, la costruzione delle colonne portanti l'esagono della cupola, la quota pavimentale dell'ambiente sottostante il coro fu abbassata di circa $1,90 \mathrm{~m}^{50}$ (Fig. 18). Scandito in tre navate

\footnotetext{
${ }^{49} \mathrm{La}$ cupola fu terminata nel 1263 quando fu acquistato il piombo per la sua copertura e conclusa nel 1264 con l'acquisto del rame per la «mela» che la coronava. ${ }^{50}$ Le fondazioni del pilastro nord del coro mostrano chiaramente la trasformazione subita: il basamento quadrangolare, in vista dopo l'abbassamento della quota pavimentale, fu scalpellato in modo da prolungare il fusto ottagonale del pilastro. Analogamente, nella facciata orientale gli stipiti dell'ingresso laterale destro mostrano una cesura tra la porzione inferiore e quella superiore della muratura, conseguenza anch'essa dell'abbassamento del piano pavimentale interno all'ambiente.
} 

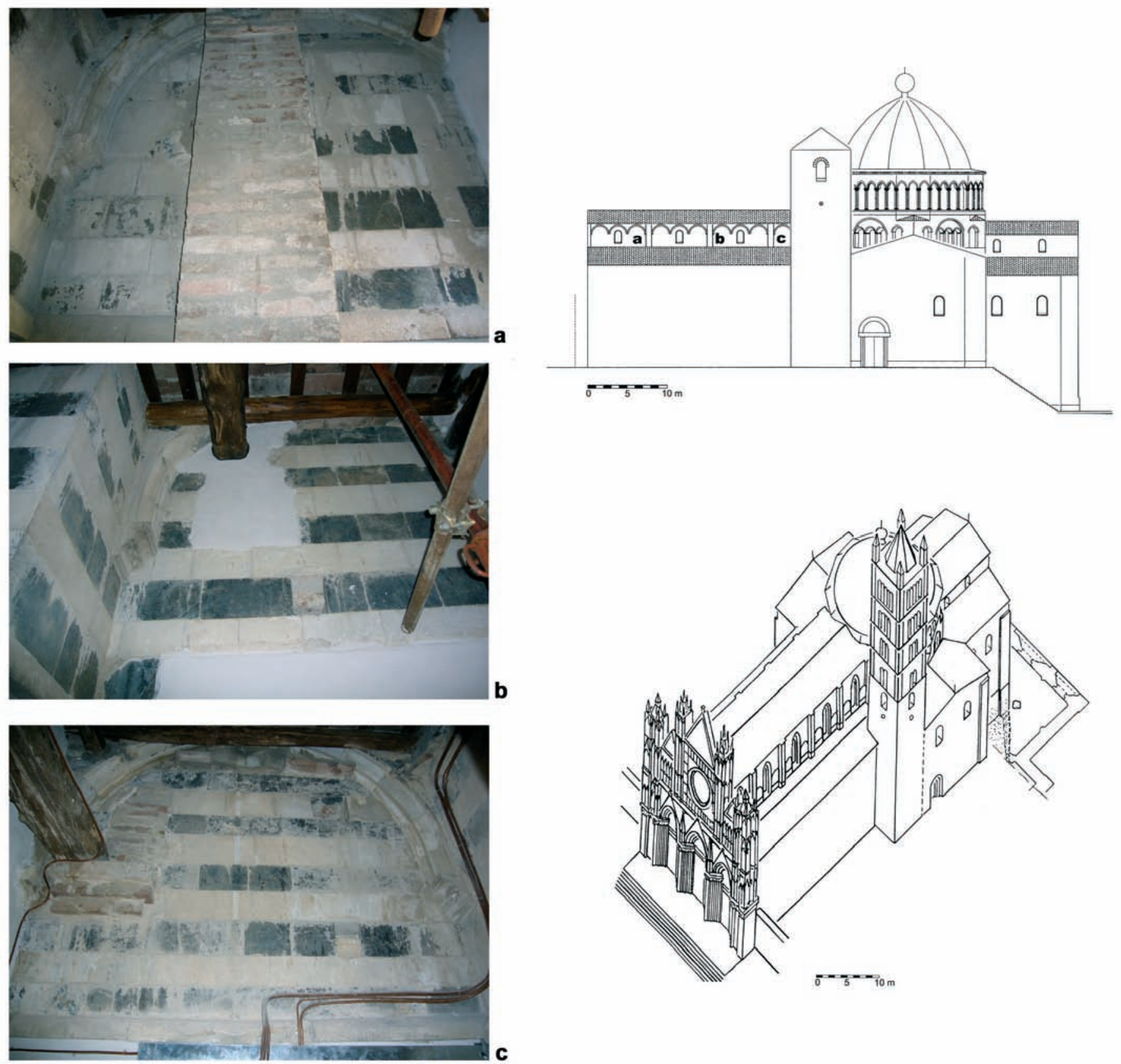

Fig. 17. Ricostruzione del Duomo di Siena nel 1284, in alto, e nel 1317, in basso (da Haas, von Winterfeld 2006). A lato, tre particolari del rivestimento marmoreo e del sistema ad archi ciechi della cattedrale duecentesca

dai due pilastri ottagonali del coro, l'ambiente fu delimitato ad ovest da un muro in laterizi sul quale si impostavano due semicapitelli decorati, posti a sostegno del nuovo sistema di copertura dell'ambiente, a volte a crociera costolonata (Vigni 2006).

Il vano confermava così la sua funzione di vestibolo di accesso orientale alla cattedrale superiore - il collegamento era garantito da un passaggio interno, situato nell'angolo ovest dell'ambiente - e la sua importanza è sottolineata dall'originalità, anche sul piano progettuale, dei lavori condotti nell'ambiente ${ }^{51}$ : alle opere di ampliamento e decoro architettonico, segue la realizzazione di un sontuoso ciclo pittorico, databile agli anni ' 80 del XIII secolo, e di una pavimentazione in laterizi.

Nel corso dei primi anni del XIV secolo l'angolo occidentale dell'ambiente fu trasformato: le scale che conducevano alla cattedrale superiore furono tolte e al loro po-

\footnotetext{
${ }^{51}$ L'adozione di volte a crociera, soluzione ancora relativamente innovativa in ambito senese, consentì infatti di mantenere il sistema di accessi posteriori alla
} cattedrale. 

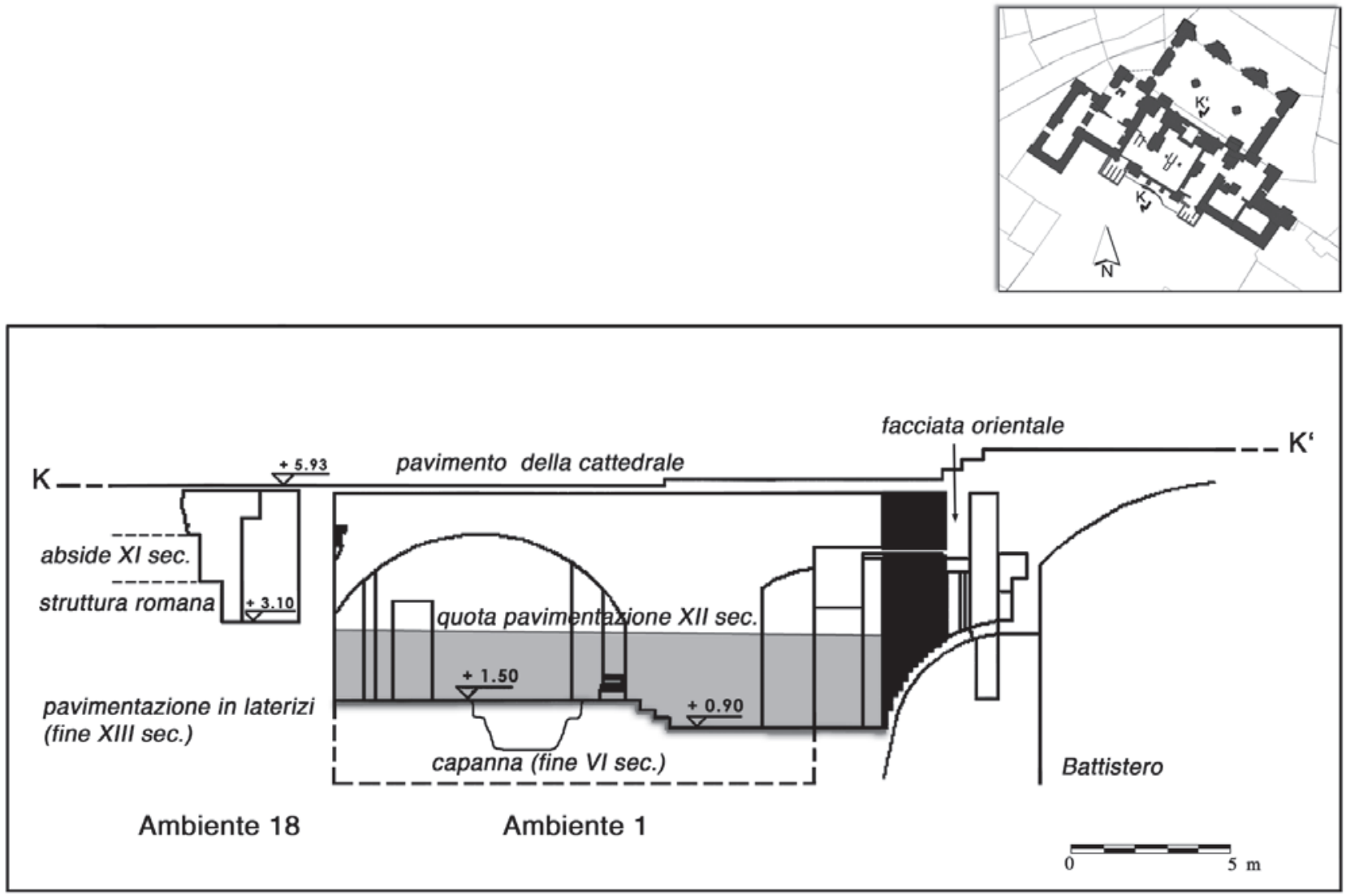

Fig. 18. Sezione trasversale dei locali sotto il coro: in evidenza le quote pavimentali dell'ambiente affrescato all'inizio e alla fine del xIII secolo

sto fu costruito un muro in laterizi, di limitato spessore: in questo periodo, dunque, l'unico ingresso era garantito dalle aperture nella facciata. Solo in un secondo momento, quando probabilmente era già stata avviata la costruzione del Battistero (iniziata nel 1317), fu aperta una porta «di servizio» nella parete perimetrale nord-ovest dell'ambiente, creando così un collegamento con il vano adiacente.

A questa fase è attribuibile infine un primo ampliamento del braccio nord del transetto, di cui si ha testimonianza nelle murature perimetrali degli ambienti con accesso da via dei Fusari (Ambiente 10). E' caratterizzato da una muratura formata da filari alterni di mattoni e pietra, in conci di calcare cavernoso squadrati e spianati, databile, in base alla tecnica edilizia (Tipo 2), all'inizio del XIV secolo, periodo di poco precedente i lavori di ampliamento della cattedrale verso Vallepiatta.

Fase IV (1315-metà XIV secolo) - Le grandiose opere intraprese in questa fase videro, dopo il 1315, l'ampliamento del Duomo verso Vallepiatta, l'edificazione del nuovo Battistero e la costruzione del cosiddetto «Duomo
Nuovo" ${ }^{52}$, ambizioso progetto edilizio destinato a sostituire la 'vecchia' cattedrale: iniziato nell'inverno 1339/ $40 \mathrm{fu}$ bruscamente interrotto e poi abbandonato nel 1355 , in seguito al manifestarsi di gravi problemi strutturali ${ }^{33}$.

Entro il 1317, anno in cui il cantiere si spostò nella parte orientale della cattedrale per l'ampliamento del transetto e del coro, fu completato il registro superiore della facciata occidentale e, probabilmente, anche la sopraelevazione della navata maggiore. Ciò comportò il conseguente innalzamento delle navate laterali e del relativo sistema di copertura, con l'obliterazione degli archetti pensili, asportati dall'apertura delle grandi trifore che illuminano oggi la navata centrale del Duomo.

\footnotetext{
52 Di questi progetti si conservano quattro pergamene, conservate presso il museo dell'Opera del Duomo di Siena: una con il progetto per la facciata del Battistero di San Giovanni, due relative a due distinti progetti di costruzione del Duomo Nuovo e la quarta relativa al suo campanile (Carli 1979, pp. 21-24; Borgherini 2001).

${ }^{53}$ Per un'approfondita analisi delle vicende relative all'ampliamento del Duomo verso Vallepiatta, alla costruzione e all'abbattimento del Duomo Nuovo, alla conseguente ripresa dei lavori interrotti nella vecchia cattedrale, si veda Giorgi, Moscadelli 2005, pp. 91-104 ed i relativi riferimenti bibliografici .
} 

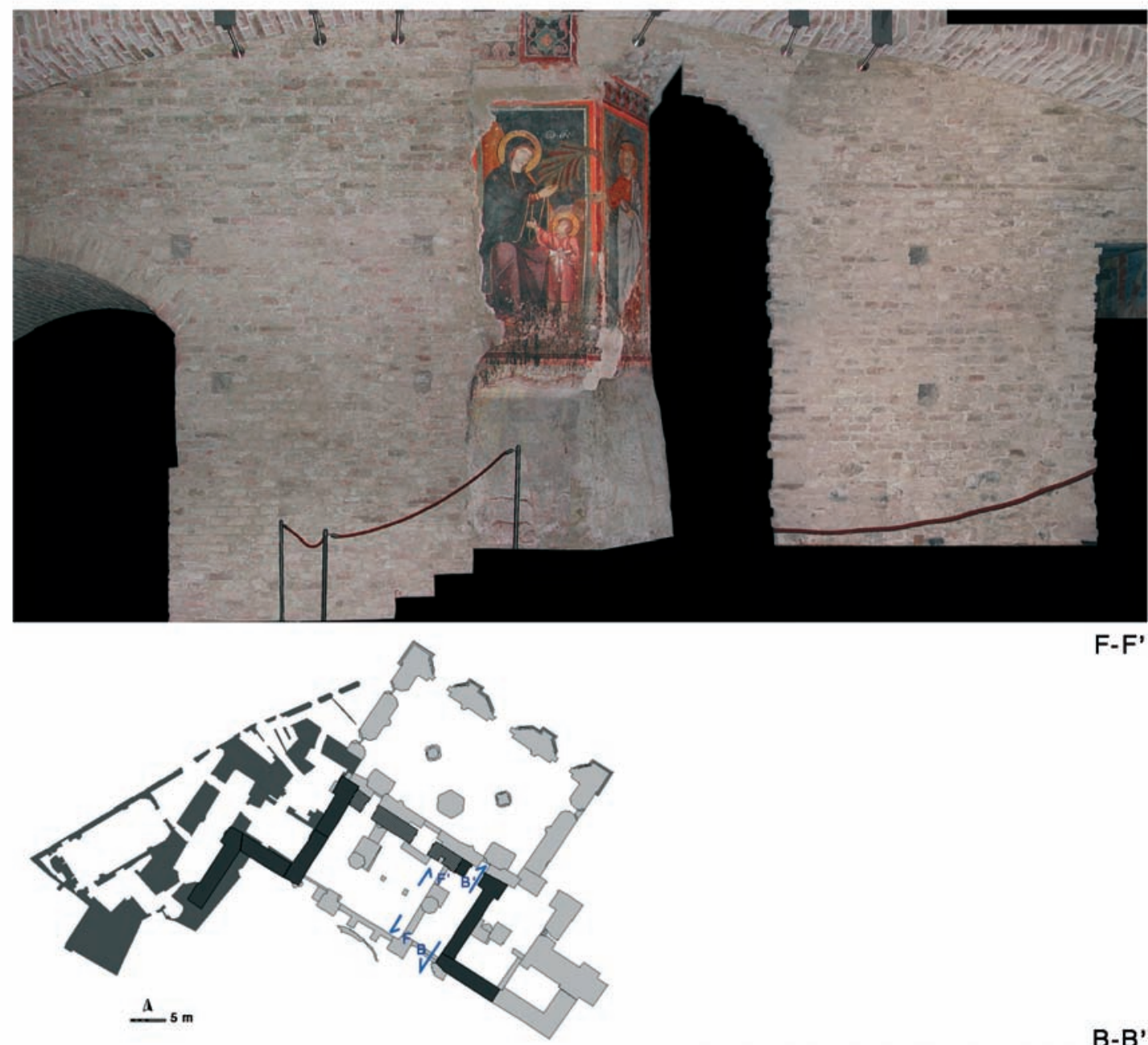

F-F'

B-B'

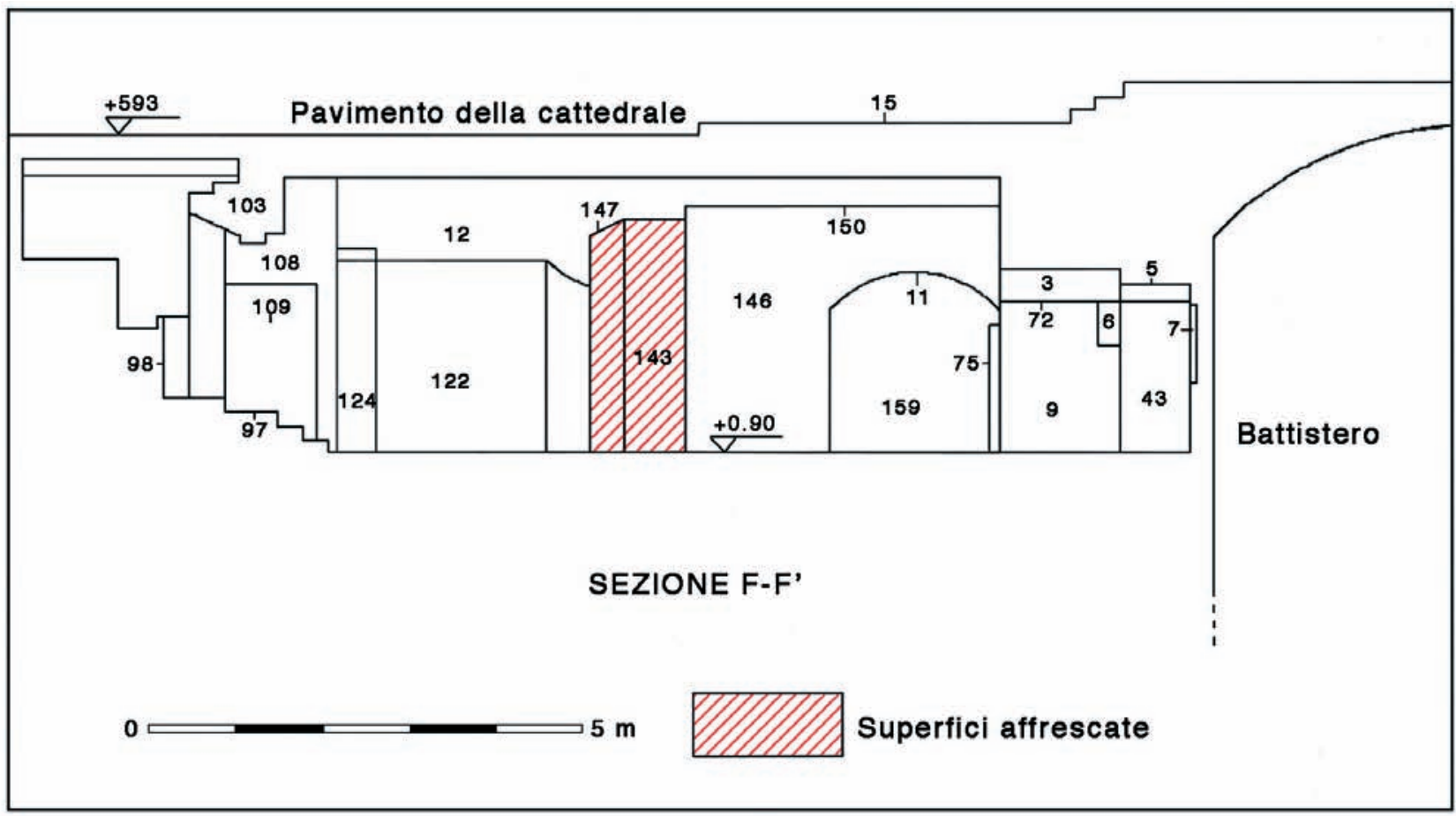

Fig. 19. Ambiente affrescato: in alto, fotoraddrizzamento del prospetto $F-F^{\prime}$ con al centro il pilastro ottagono duecentesco e le fondamenta di quello trecentesco; in basso, eidotipo del prospetto B-B' con in evidenza le principali Unità Stratigrafiche Murarie 
Nel 1317 prese avvio l'accrescimento della cattedrale verso Vallepiatta, con la costruzione di una serie di locali annessi di grandi dimensioni (Ambiente 7) e l'edificazione del sottostante Battistero, la cui costruzione procedette piuttosto velocemente. Il nuovo complesso, addossato alla cattedrale, ne tamponò la facciata orientale: l'ambiente affrescato, utilizzato probabilmente nei decenni successivi come locale funzionale al cantiere all'opera per l'edificazione del nuovo coro $^{54}$, vide di conseguenza un progressivo abbandono delle sue strutture.

I lavori subirono un'interruzione tra il 1339 ed il 1355 dopodichè, abbandonato definitivamente il progetto di costruzione del Duomo Nuovo, ripresero con l'ampliamento del coro della cattedrale.

Durante la seconda metà del XIV secolo si demolirono parte delle volte a crociera poste a copertura dell'ambiente affrescato per procedere alla costruzione delle strutture di fondazione dei due nuovi pilastri del sovrastante coro $^{55} \mathrm{e} \mathrm{di}$ due grandi archi di scarico ad essi collegati, impostati nelle pareti perimetrali del vestibolo (Fig. 19). Demolite le strutture del coro duecentesco, i nuovi pilastri furono costruiti circa $1 \mathrm{~m}$ a nord-est rispetto ai pilastri della precedente struttura, per l'esigenza di un giusto rapporto dimensionale (CARLI 1979, p. 20). Nel vano sottostante il coro, le nuove strutture andarono quindi ad insistere in parte sulle nuove fondazioni, in parte sui pilastri ottagonali del 'vecchio' coro.

I lavori per il prolungamento absidale della cattedrale terminarono intorno alla metà degli anni Sessanta del Trecento (Giorgi, Moscadelli 2005, p. 105).

Fase V (prima metà XV secolo) - Questa fase sancisce il definitivo abbandono dell'ambiente sottostante il coro: nel corso della prima metà del $\mathrm{XV}$ secolo infatti le aperture della facciata, che continuarono ad essere in uso probabilmente per tutta la durata del cantiere, furono tamponate ${ }^{56}$ ed il vano fu colmato da livelli di terra e detriti con materiali databili alla prima metà del XV secolo.

Intorno agli anni '20 fu costruita, per l'alloggio del nuovo fonte battesimale, l'abside del Battistero: la sua

\footnotetext{
${ }^{54}$ Questo spiega la presenza, nel muro perimetrale sud-ovest del Battistero, di tre aperture poi tamponate - uguali per ampiezza e dimensioni agli ingressi duecenteschi della facciata orientale - che permettevano un facile accesso tra la zona dei lavori e la cattedrale. Al centro del vano affrescato inoltre è stato trovato un grande taglio di forma circolare, riempito da materiale edilizio di scarto, terra e resti di lavorazione di materiale lapideo e marmoreo.

${ }^{55}$ L'indagine stratigrafica ha rivelato la presenza, nelle fosse di fondazione di queste strutture, di maiolica arcaica databile alla seconda metà del XIV secolo.

${ }^{56} \mathrm{Fa}$ eccezione l'ingresso laterale posto a nord-est, tamponato probabilmente nel corso del XIV secolo.
}

edificazione comportò la distruzione di parte del portale centrale della facciata orientale duecentesca e delle murature circostanti. Per impedire che il riempimento dell'ambiente gravasse sull'estradosso della volta dell'abside, fu quindi innalzata una struttura in laterizi e materiale lapideo di riutilizzo che si impostava sulle murature affrescate della facciata interna (Fig. 20).

Con la costruzione di un muro di separazione tra la 'navata' laterale sud-est e la parte restante del vestibolo affrescato, fu risparmiata dall'abbandono solo questa parte del vano; il nuovo locale - noto come "Cripta delle Statue» - continuò a comunicare con gli ambienti adiacenti e da lì con l'esterno grazie ad un nuovo ingresso, aperto nelle murature in pietra del coro di XII secolo.

Fase VI (fine XVI secolo-inizio XVIII secolo) - Tra la fine del XVI e la prima metà del XVIII secolo parte del riempimento dell'ambiente fu svuotato al fine di costruire una serie di loculi in mattoni, coperti con una volta a botte e con i muri perimetrali lunghi in comune ${ }^{57}$.

Nel corso del XVII secolo furono costruite alcune strutture di rinforzo in laterizi poggianti direttamente sui livelli di riempimento sottostanti; sono probabilmente da mettere in relazione allo spostamento del pulpito di Nicola Pisano che, situato in origine sotto la cupola, fu trasportato in epoca moderna nella posizione attuale. La parte del vestibolo affrescato ancora accessibile, fu utilizzata come deposito per i legnami da costruzione.

I locali sottostanti al braccio sinistro del transetto furono in parte trasformati e suddivisi con la costruzione di setti murari realizzati in pietre non lavorate e mattoni di scarto, posti in opera in maniera irregolare (Tipo 7).

Tra la metà del Cinquecento e il 1798, il corpo basilicale del Duomo fu rinforzato con l'aggiunta di una serie di contrafforti esterni. In questi anni, infatti, Siena fu colpita da una serie di terremoti ${ }^{58}$ che indebolirono le strutture portanti della navata laterale sinistra e del cleristorio della cattedrale, con la conseguente necessità di costruire una serie di contrafforti esterni in laterizi ad arco rampante sul fianco ovest (1694) e ad arco convesso sulle pareti della navata maggiore (1800).

\section{TECNICHE E MAESTRANZE: NOTE CONCLUSIVE}

Data la complessità delle tematiche trattate ed i numerosi studi inerenti ad esse, in questa sede ci si limita a sottolineare l'apporto che le indagini di scavo, la lettura

\footnotetext{
${ }^{57} \mathrm{Si}$ veda supra, 1.2 .

${ }^{58}$ In particolare i terremoti del 1558, del 1691 e del 1798 (Sembranti 1995).
} 

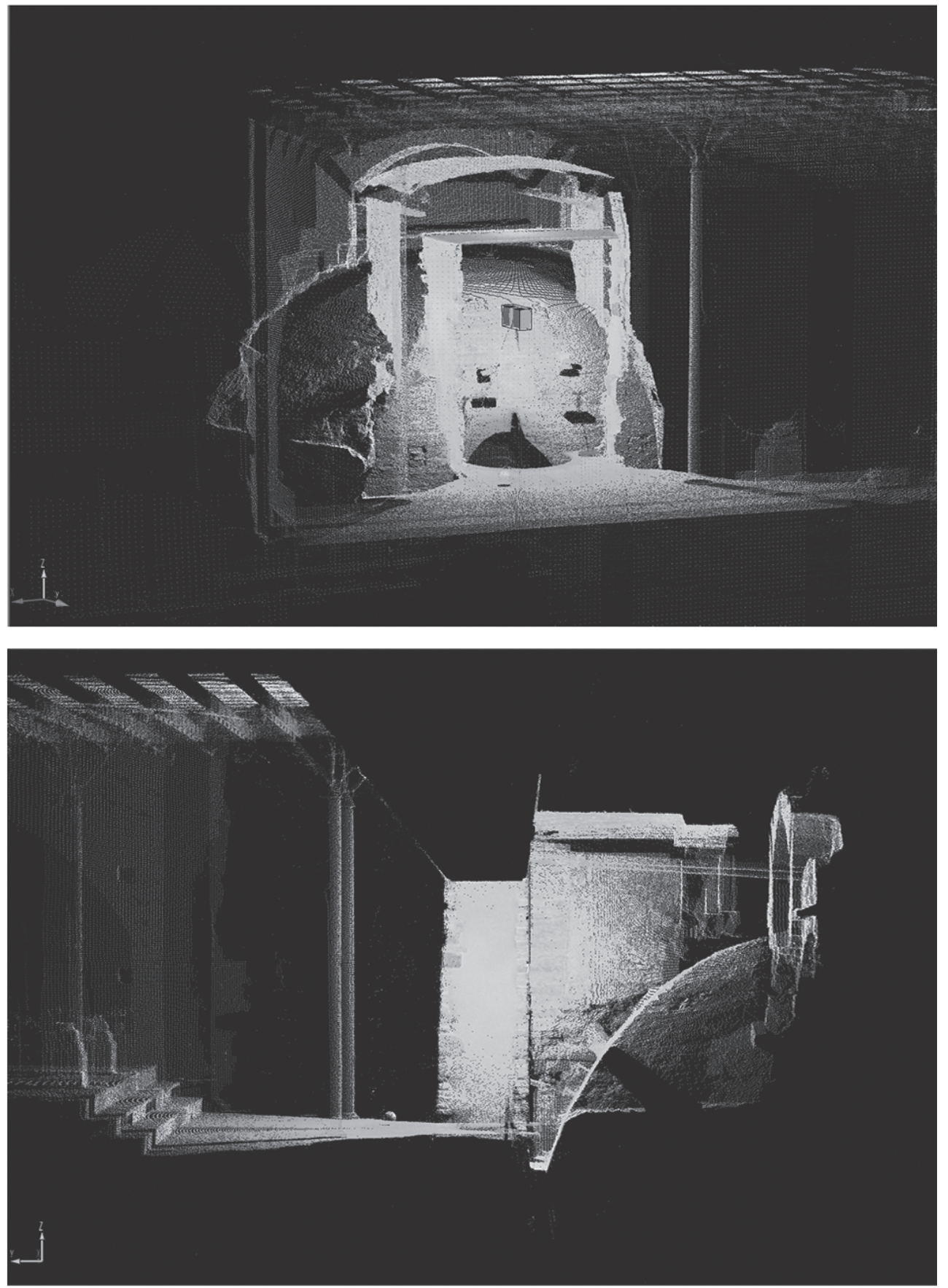

Fig. 20. Rilievo 3D dell'ambiente affrescato sotto il coro del Duomo: particolari dell'abside del Battistero visibile all'interno del vano (Università di Siena, Area di Archeologia Medievale, LIAAM)

degli elevati e lo studio dei materiali adoperati in fase di cantiere possono portare alla conoscenza dell'evoluzione di un monumento come la cattedrale di Siena.

Le ricerche condotte nella parte absidale del Duomo e nel cleristorio hanno permesso, da un lato, l'elaborazione di una precisa scansione dei tempi di avanzamento del cantiere tra XII e XIV secolo, dall'altro, hanno portato nuovi dati sul lavoro e l'organizzazione delle maestranze che operarono tra Duecento e primi decenni del Trecento nel progressivo ampliamento della cattedrale. Per quanto ri- guarda invece l'XI e, in particolare, il XII secolo, l'analisi delle modalità e dei tempi di costruzione impiegati nella posa in opera delle strutture della cattedrale non può essere svolta - in base ai dati oggi in nostro possesso - in modo esaustivo. Per questo periodo, ci limiteremo perciò allo studio del materiale da costruzione impiegato, indicativo di una scelta precisa e di un forte legame con Siena.

L'utilizzo esclusivo in questa fase, infatti, di conci in calcare cavernoso per la realizzazione dell'edificio più rappresentativo della città evidenzia una scelta in perfetta 
consonanza con l'architettura senese del medesimo periodo, allorché numerose costruzioni vengono realizzate con il calcare locale - chiamato anche, non a caso, "pietra da torre» - e con tecnica edilizia e tipologia muraria simile (Tipo 1); con maestranze che lavorano ad una cattedrale, che si può definire già da allora "cittadina», con gli stessi strumenti impiegati nei cantieri urbani, principalmente l'ascettino a lama piana e lo scalpello (Cataldo 2003, p. 119), ampiamente diffusi anche nel territorio.

L'uso 'politico' nella scelta del materiale, nell'edificazione di edifici di particolare rilevanza in ambito urbano, è confermato anche - all'inizio XIII secolo - dalla costruzione di un raffinato rivestimento in pietra per la facciata orientale del Duomo. Per quest'opera si utilizzano conci perfettamente squadrati e spianati con l'uso dello scalpello per il nastrino e di uno strumento a lama dentata, una martellina dentata a punte fini non attestata prima a Siena, per la faccia a vista del concio.

La martellina dentata, uno degli strumenti più diffusi nell'architettura medievale europea, sarà infatti largamente impiegata in Toscana, e a Siena in particolare, solo a partire dal XIV secolo, ma nel territorio pisano, volterrano ed in Valdelsa compare già tra la seconda metà del XII ed il XIII secolo (Mennucci 1996, pp. 51-54). In area senese il più antico impiego della martellina dentata è attestato nella chiesa di San Galgano a Montesiepi, databile tra la fine del XII ed i primi anni del XIII secolo e, a partire dagli anni '20 del XIII secolo, nelle murature in pietra della vicina abbazia cistercense, dedicata sempre a San Galgano (Gabbrielli 1998, pp. 19-21).

Un ulteriore punto di incontro tra la «rotonda» di Monte Siepi e il Duomo si riscontra nell'uso, in entrambe le fabbriche, di laterizi graffiati analoghi, realizzati e posti in opera negli stessi anni, l'inizio del Duecento, con uno strumento a lama piana (Gabbrielli 2003, p. 43). Entrambi questi edifici - e di lì a pochi anni anche il grande cantiere per l'edificazione dell'abbazia di San Galgano ${ }^{59}$

\footnotetext{
${ }^{59}$ Il tema dei «monaci costruttori», caro a molta storiografia cistercense, è stato recentemente affrontato da F. Gabbrielli nell'ottica di un approfondito studio sulla formazione, la circolazione e la composizione dei diversi gruppi di maestranze all'opera nel cantiere dell'abbazia di San Galgano tra gli anni '20 del Duecento e la fine del secolo (Gabbrielli 1998; Gabbrielli 2000): l'autore esclude «un vasto e generalizzato impiego di maestranze religiose direttamente coinvolte nell'attività costruttiva, almeno per quel che riguarda le strutture murarie» (Gabbrielli 2000, p. 61). Nel cantiere dell'abbazia di San Galgano fin dagli anni '60-'70 del XIII secolo sono all'opera maestranze di provenienza 'senese', a cui si deve il completamento delle navate, mentre sono riconducili alla bottega di Nicola Pisano e al Duomo di Siena gli scalpellini all'opera nella realizzazione dei gruppi di capitelli posti in opera nel corpo longitudinale dell'edificio (Gabbrielli 2000, pp. 58-60). Per un riepilogo delle posizioni pro e contro l'ipotesi dei monaci costruttori, si veda Gimpel 1980, pp. 99-102.
}

rappresentano, pur in una diversa scala di valori, episodi architettonici 'speciali', anticipatori ed esportatori di soluzioni tecniche e formali.

Non a caso, dunque, in questi anni l'utilizzo della martellina è attestato per la prima volta a Siena nella facciata orientale della cattedrale e, a partire dalla seconda metà del Duecento, sarà impiegato in maniera sistematica dalla manodopera attiva nel Duomo mentre, in ambito urbano, troverà ampia diffusione solo nei decenni successivi (Bianchi, Parenti 1991, p. 144) ${ }^{60}$.

E' da segnalare inoltre come, in concomitanza con la ripresa economica del XIII secolo, all'inizio del Duecento le maestranze all'opera nella parte absidale del Duomo utilizzino, nella stessa fase, l'ascettino per lavorare i mattoni e la martellina dentata per i conci di calcare della facciata.

Tra gli anni '60 del Duecento ed il primo trentennio del Trecento, diversi cantieri si sono succeduti nell'ampliamento verso Vallepiatta della cattedrale e nella trasformazione del corpo anteriore: il cantiere sotto le direttive di Nicola Pisano per la costruzione della cupola, ante 1268; il cantiere per la trasformazione e la decorazione del vestibolo di accesso orientale alla cattedrale, negli anni '70-' 80 ; il cantiere che seguì la costruzione delle navate, ante 1284; il cantiere guidato da Giovanni Pisano per l'ampliamento del corpo basilicale di una campata e la costruzione della nuova facciata occidentale, ante 1296-1297; il cantiere per la conclusione della facciata e la sopraelevazione della navata centrale, ante 1317; il cantiere per la costruzione del Battistero, post 1317.

L'indagine condotta sui materiali da costruzione impiegati nelle fondamenta delle strutture e nelle murature degli ambienti annessi alla cattedrale, conferma un sostanziale riscontro tra i materiali impiegati dalla fabbrica in questi decenni e quelli delle architetture cittadine, con un preponderante utilizzo dei laterizi (Tipo 3 e 4) e - nei decenni a cavallo tra Due e Trecento - un uso limitato di pietra e mattoni organizzati su filari alternati (Tipo 2).

Tutte le murature a vista del Duomo sono ora rivestite di marmo. L'analisi mensiocronologica condotta su alcuni campioni di paramento, databili tra gli anni '60 e gli anni '80 del XIII secolo, la fine del XIII secolo ed il primo quarto del Trecento, hanno fornito utili indicazioni sul ciclo produttivo e le tecniche impiegate in quegli anni.

In particolare, si nota che la bicromia dei paramenti marmorei databili alla seconda metà del Duecento mantiene misure analoghe sia nella cupola che nelle navate (dai

\footnotetext{
${ }^{60}$ In altre città toscane, come Firenze ad esempio, questo strumento è attestato nei grandi cantieri urbani non prima degli ultimi due decenni del XIII secolo, a conferma della precocità del suo utilizzo nel territorio senese.
} 
18 ai $22 \mathrm{~cm}$ ): solo con il cantiere di Giovanni Pisano si comincia ad osservare un progressivo aumento nelle altezze dei filari di marmo bianco (dai 22 ai $26 \mathrm{~cm}$ ), forse con un intento di 'correzione ottica'. Le misure costanti e ricorrenti (conci di serpentino di 20 o $22 \mathrm{~cm}$; conci di marmo di 22 o $26 \mathrm{~cm}$ ) vengono però incontro anche ad altre esigenze, non solo estetiche: permettevano infatti di organizzare il ciclo produttivo già nella cava di provenienza del materiale lapideo (la cosiddetta petraia), dove poteva essere prodotto 'in serie' 61.

Questa tendenza si conferma anche nel cantiere trecentesco: la produzione di serpentino è fissata in conci con altezza standard di $20 \mathrm{~cm}$, mentre l'approvvigionamento di marmo bianco, impiegato in quantità maggiore, si organizza intorno a misure fisse, di $20 \mathrm{~cm}$ o $26-28 \mathrm{~cm}$ confermando anche in questo caso che i materiali lapidei di rivestimento erano prodotti secondo procedure standardizzate di 'prefabbricazione', sia che la lavorazione avvenisse nella cava di estrazione oppure in laboratorio, la taglia, situata a Siena presso la sede dell'Opera.

I laterizi impiegati nelle murature di alcune strutture di servizio in mattoni annesse al Duomo, databili anch'esse ai primi decenni del Trecento, mostrano invece tracce di lavorazione con finalità e tecniche di realizzazione completamente diverse dai laterizi graffiati di inizio Duecento dell'ambiente affrescato. In particolare nella grande sala (Ambiente 7) situata lungo via dei Fusari, edificata in concomitanza ai lavori per il Battistero ma mai portata a termine, la graffiatura dei laterizi riguarda solo gli elementi architettonici mentre le superfici murarie non presentano alcun tipo di lavorazione. In questo caso però il trattamento è una traccia residua di una lavorazione a lama piana di elementi speciali destinati ad essere arrotati e, pertanto, a rimanere a vista.

Lo studio degli strumenti impiegati per la lavorazione dei paramenti dalle maestranze attive nel Duomo tra inizio Duecento ed i primi decenni del Trecento - principalmente strumenti a lama piana come l'ascettino o dentata come la martellina - può servire a precisarne l'ambito culturale di formazione. Accanto ad una qualificata presenza pisana e fiorentina, la documentazione scritta non fornisce, infatti, altri indizi relativi all'origine dei maestri, tanto da fare supporre una forte presenza di maestranze senesi ${ }^{6}$.

Gli scalpellini attivi nel corso del XIII secolo utilizzarono, per la finitura dei materiali lapidei, la martellina

${ }^{61}$ Sulla prefabbricazione, la lavorazione 'in serie' del materiale lapideo e l'organizzazione del cantiere, si vedano Bechmann 1984; Kimpel 1977, Kimpel 1989; Coppola 1996.

${ }^{62}$ Cfr. nota 59 e Giorgi, Moscadelli 2005, pp. 241-245. dentata a punte fini ${ }^{63}$ - con un orientamento obliquo dei colpi nella prima fase mentre alla fine del secolo si predilige un orientamento sia in orizzontale che in verticale - e l'ascettino per il trattamento dei laterizi. Nei primi decenni del Trecento, invece, nelle murature del rialzamento della navata centrale si preferisce utilizzare una martellina dentata a punte grosse, mentre il trattamento dei laterizi è limitato ai soli elementi architettonici e alla graffiatura con funzioni 'estetiche' e decorative, come nel secolo precedente, si preferisce l'arrotatura.

L'impiego estensivo nella lavorazione dei paramenti lapidei di un particolare strumento di finitura, la martellina dentata, da parte dei gruppi che si succedettero nel cantiere tra XIII e prima metà XIV secolo, ci conferma il ricco bagaglio tecnico raggiunto dalle maestranze attive nel territorio senese, tramandatosi dal primo apparire dello strumento nella facciata orientale, all'inizio del secolo, ai decenni centrali del Duecento con le maestranze operanti nel corpo basilicale sotto Nicola Pisano (anni '60-'80), nel ventennio seguente al cantiere di Giovanni (anni '90) e infine nelle grandi opere trecentesche.

\section{Bibliografia}

Argenziano, R., 2000, Agli inizi delliconografia sacra a Siena. Culti, riti e iconografia a Siena nel XII secolo, Firenze.

Arnoldus-Huyzendveld, A., 2002, Risultati delle indagini geoarcheologiche effettuate allo scavo archeologico sotto il Duomo di Siena, finalizzate in particolare alla ricostruzione della forma pre-urbana del paesaggio (2002), relazione interna per l'Università degli Studi di Siena.

Bacci, P., 1944, Documenti e commenti per la storia dell'arte, Firenze.

Bagnoli, A., 1981, Novità su Nicola Pisano scultore nel duomo di Siena, «Prospettiva», 27 (ottobre 1981), pp. 27-46.

Bagnoli, A., 2003, Alle origini della pittura senese. Prime osservazioni sul ciclo dei dipinti murali, in Guerrini 2003, pp. 107-151.

Balestracci, D.; Piccinni, G., 1977, Siena nel Trecento. Assetto urbano e strutture edilizie, Firenze.

Bechmann R., 1984, Le radici delle cattedrali, Casale Monferrato.

Bianchi, G., 1988-89, Mattoni e pietre. Lo studio delle tecniche costruttive a Siena dal XII al XVIII secolo, Tesi di laurea, Facoltà di Lettere e Filosofia, Università degli Studi di Siena, rel. prof. R. Francovich.

Bianchi, G., 1991, Il ruolo del mattone a Siena nell'edilizia medievale e moderna, in Aa.VV., Fornaci e mattoni a Siena. Dal XIII secolo all'azienda Cialfi, Siena, pp. 11-20.

Bianchi, G.; Parenti, R. 1991, Gli strumenti degli 'scalpellini' toscani. Osservazioni preliminari, in Biscottin G., Mietto D. (a cura di), Le pietre nell'architettura. Struttura e Superfici, Atti del Convegno di studi (Bressanone, 25-28 Giugno 1991), Padova, pp. 139-149.

Boldrini, E.; Parenti, R. (a cura di), 1991, Santa Maria della Scala, Archeologia e edilizia sulla piazza dello Spedale, "Biblioteca di Archeologia Medievale», 7, Firenze.

\footnotetext{
${ }^{63}$ In particolare, le maestranze di seconda metà Duecento attive nella cattedrale impiegano in modo quasi esclusivo un tipo di martellina dentata con i due trancianti di dimensioni ridotte rispetto alla norma (di solito compresa tra i 7 ed i $9 \mathrm{~cm}$ ), non superiore ai $5,5 \mathrm{~cm}$ per ogni lato e con un numero di denti superiore alla media (12-14 punte): è uno strumento più leggero e maneggevole della normale martellina dentata, utilizzato al fine di raggiungere una migliore spianatura delle superfici a vista (Causarano 2009, p. 776).
} 
Borgherini, M., 2001, Disegno e progetto nel cantiere medievale. Esempi toscani del XIV secolo, Venezia.

Bossio et al., 1995 = Bossio, A.; Costantini, A.; Foresi, L.M.; Lazzaretto, A.; Lotta, D.; Mozzanti, R.; Mazzei, R.; Salvatorini, G.; Sandrelli, F., Studi preliminari sul sollevamento della Toscana meridionale dopo il Pliocene medio, in Geodinamica e tettonica attiva nel sistema Tirreno-Appennino, a cura di G. Cello, G. Deiana, P.P. Pierantoni, Atti del Convegno di Studi (Camerino, 910 febbraio 1995), Camerino, pp. 87-92.

Brogini, P., 1991-92, Lo sviluppo urbanistico di Siena fino all'età precomunale, Tesi di laurea, Facoltà di Lettere e Filosofia, Università degli Studi di Siena, rel. prof. D. Balestracci.

Butzek, M., 2006, Chonologie, in Haas, von Winterfeld 2006, pp. 1-262.

Bratto, T., 2003, Il cantiere sotto il duomo, in Guerrini 2003, pp. 169-190.

Cantini, F., 2005, Archeologia urbana a Siena. L'area dell'Ospedale di Santa Maria prima dell'ospedale. Altomedioevo, Firenze.

Cantini et al., 2006 = Cantini, F.; Francovich, R.; Valenti, M., Scavi nella città di Siena, in Le città italiane tra la tarda Antichità e l'alto Medioevo, a cura di A. Augenti, Atti del Convegno (Ravenna, 26-28 febbraio 2004), Firenze, pp. 273-298.

Carli, E., 1979, Il Duomo di Siena, Genova.

Cataldo, C., 2003, L'architettura in pietra a Siena tra i secoli XI e XV: ricognizione e studio sul territorio urbano, "Archeologia dell'Architettura», VIII (2003), pp. 113-122.

Causarano, M.A., 2005, Interventi archeologici sotto il duomo di Siena, in Archeologia dei Paesaggi Medievali. Relazione Progetto (2000-2004), a cura di M. Valenti, R. Francovich, Firenze, pp. 21-34.

Causarano, M.A., 2009, La cattedrale di Siena tra seconda metà XIII e XIV secolo: trasformazioni e ridefinizione dell'edificio, in $V$ Congresso Nazionale di Archeologia Medievale, a cura di G. Volpe, P. Favia (Foggia - Manfredonia, 30 settembre-3 ottobre 2009), Firenze, pp. 773-778.

Causarano, M.A.; Tronti, C., 2005, Lo scavo di emergenza di via Baroncelli, in Archeologia dei Paesaggi Medievali. Relazione Progetto (2000-2004), a cura di M. Valenti, R. Francovich, Firenze, pp. 51-55.

Causarano et al., 2003 = Causarano, M.A.; Francovich, R.; Valenti, M. 2003, Lintervento archeologico sotto il duomo di Siena: dati e ipotesi preliminari, in Guerrini 2003, pp. 153-168.

Censini et al., 1993 = Censini, G.; Focardi, P.; Gentili, P.; Senatro, I.; Lazzarotto, A., Studio geologico volto alla definizione della consistenza statica e della vulnerabilità sismica del Duomo di Siena in Aa.Vv, Il Duomo di Siena. Documenti, studi, restauri, Soprintendenza per i Beni Ambientali e Architettonici di Siena e Grosseto, Siena, pp. 43-59.

Commella, A.; Mele, S. (a cura di), 2006, Depositi votivi e culti dell'Italia antica dall'età arcaica a quella tardo-reppublicana, Atti del convegno di studi (Perugia, 1-4 giugno 2000), Bari.

Coppola, G., 1996, Cave di pietra e tecniche d'estrazione: elementi di conoscenza dell'architettura medievale, in La pietra dei monumenti nel suo ambiente fisico, a cura di R.A. Lefevre, Roma, pp. 65-81.

Corsi, R., 1988-89, Mattoni e pietre. Le variazioni dimensionali dei laterizi da costruzione a Siena dal XIII al XIX secolo, Tesi di laurea, Facoltà di Lettere e Filosofia, Università degli Studi di Siena, rel. prof. R. Francovich.

Corsi, R., 1991, Forma, dimensioni e caratteristiche del mattone senese, in Fornaci e mattoni a Siena. Dal XIII secolo all'azienda Cialfi, Siena, pp. 21-30.

Costantini, A., 1999, Siena sotterranea, in L'immagine di Siena. Le due città. Le piante degli acquedotti sotterranei di Siena nelle collezioni cittadine (dal XVI al XIX secolo), Catalogo della mostra (Siena, 25 marzo - 9 maggio 1999), Siena, pp. 17-21.

Francovich, R., 2005, Alcune note sulle recenti ricerche di archeologia medievale a Siena, in L'Italia alto-medievale tra archeologia e storia. Studi in onore di Ottone d'Assia, a cura di S. Gelichi, Padova, pp. 131-150.

Francovich, R.; Valenti, M., 2006, Il passato come risorsa, in Siena tra fedeltà e innovazione, a cura di R. Barzanti, E. Zanchi, «Il Ponte», 62, n. 5-6, Firenze, pp. 186-201.

Gabbrielli, F., 1995, Stilemi senesi e linguaggi architettonici nella Toscana del DueTrecento, in L'architettura civile in Toscana. Il Medioevo, a cura di A. Restucci, Cinisello Balsamo, pp. 305-368.

Gabbrielli, F., 1998, La chiesa dell'abbazia di San Galgano. I. Stereotomia degli archi e fasi costruttive, "Archeologia dell'Architettura», III, pp. 15-44.
Gabbrielli, F., 2000, La chiesa dell'abbazia di San Galgano. II. Stereotomia degli archi e maestranze, "Archeologia dell'Architettura", V, pp. 25-61.

Gabbrielli, F., 2003, Il Duomo e San Galgano. Note sulle origini del mattone graffiato a Siena, in 'Imago Virginis'. Dall'arte delle origini alla Libreria Piccolomini, a cura di M. LORENZONI, R. GUERrini, "Quaderni dell'Opera», Anno IV- VI, 2000-2002, pp. 27-53.

Garzelli, A., 2000, Nicola Pisano e i cistercensi nel duomo di Siena, in Le vie del Medioevo, Atti del Convegno di Studi (Parma, 28 settembre-1 ottobre 1998), a cura di A.C. Quintavalle, Parma, pp. 323-345.

Gimpel, J., 1980, Les bâtisseurs de cathédrales, Paris.

Giorgi, A.; Moscadelli, S., 2001, Quod omnes cerei ad Opus deveniant. Il finanziamento dell'Opera del duomo di Siena nei secoli XIII e XIV, "Nuova Rivista Storica», LXXXV (2001), pp. 489-584.

Giorgi, A.; Moscadelli, S., 2002, L'opera di S. Maria di Siena tra XII e XIII secolo, in Chiesa e vita religiosa a Siena. Dalle origini al grande giubileo, a cura di A. Mirizio, P. Nardi, Atti del Convegno di Studi (Siena, 25-27 ottobre 2000), Siena, pp. 77-100.

Giorgi, A.; Moscadelli, S., 2003, "Ut homines et persone possint comode ingredi». Direttrici viarie e accessi orientali, in Guerrini 2003, pp. 85-105.

Giorgi, A.; Moscadelli, S., 2005, Costruire una cattedrale. L'Opera di Santa Maria di Siena tra XII e XIV secolo, in Die Kirchen von Siena, a cura di P.A. Riedl, M. Seidel, Beiheft, 3, München.

Guerrini, R. (a cura di), 2003, Sotto il duomo di Siena. Scoperte archeologiche, architettoniche e figurative, Milano.

Haas, W. †; von Winterfeld, D. (a cura di), 2006, Der Dom S. Maria Assunta. Architektur. Textband, in Die Kirchen von Siena, a cura di P.A. Riedl, M. SEIDEL, Band 3.1.1. (2 voll.), München.

Kimpel, D., 1977, Le développement del taille en série dans l'architecture médiévale et son rôle dans l'histoire économique, "Bulletin Monumental», 135 (1977), pp. 195-222.

Kimpel, D., 1989, Les methodes de production des cathédrales, in Les bâttisseurs des cathédrales gothiques, a cura di R. RECHT, Catalogo della mostra (Strasbourg, 3 septembre - 26 novembre 1989), Strasbourg, pp. 91-101.

L'Ospedale Santa Maria della Scala 2002 = L'Ospedale Santa Maria della Scala. Soria e Archeologia, a cura di M. Valenti, opera multimediale, Firenze.

Lusini, V., 1911-39, Il Duomo di Siena, voll. 2, Siena.

Mennucci, A. 1996, Maestri di pietra in Valdelsa. Attrezzatura, circolazione delle maestranze, restauri, in Aa.Vv., Chiese medievali della Valdelsa. I territori della via Francigena. Aspetti e architettonici e decorativi degli edifici romanici religiosi lungo le strade e nei pivieri valdelsani tra XI e XIII secolo, II, Tra Siena e San Gimignano, Empoli, pp. 48-55.

Milanesi, G., 1854-1856, Documenti per la storia dell'arte senese, 3 voll., Siena.

Midderdolf Kosegarten, A., 1988, Scultori senesi nel "Duomo Vecchio". Studi per la scultura a Siena (1250-1330), Siena.

Moscadelli, S., 1995, L'Archivio dell'Opera della Metropolitana di Siena. Inventario, München.

Pallecchi, S., 2004-05, Archeologia urbana a Siena: per una indagine preventiva mirata alla individuazione delle aree di maggior rischio archeologico, Tesi di Dottorato di Ricerca, Università degli Studi di Siena.

Pallecchi, S., 2006, Il palinsesto di una città medievale. Metodi e problemi dell'archeologia urbana a Siena, "Città e Storia», I (2006), 2, Roma, pp. 583594.

Parenti, R., 1995a, I materiali del costruire, in Architettura civile in Toscana. Il Medioevo, a cura di A. Restucci, Cinisello Balsamo, pp. 369-399.

Parenti, R., 1995b, Approvvigionamento e diffusione di alcuni materiali litici da costruzione dei dintorni di Siena, in Le pietre delle città d'Italia, a cura di D. Lamberini, Atti della Giornata di Studi in onore di Francesco Rodolico (Firenze, 23 ottobre 1993), Firenze, pp. 87-108.

Pietramellara, C., 1980, Il Duomo di Siena. Evoluzione delle forme dalle origini alla fine del Trecento, Firenze.

Quast, M., 2007, La facciata occidentale del Duomo Vecchio: l'architettura, in La facciata del Duomo di Siena. Iconografia, stile, indagini storiche e scientifiche, a cura di M. Lorenzoni, Milano, pp. 97-129.

Quiròs Castillo, J.A., 1997, La mensiocronologia dei laterizi della Toscana: problematiche e prospettive di ricerca, in "Archeologia dell'Architettura», II (1997), pp. 159-165. 
Redon, O., 2008, Une forêt urbane: "la Selva del Lago», in Id., Des forêts et des àmes. Espace et société dans la Toscane médiévale, Études rassemblées par Laurence Moulinier-Brogi, Saint-Denis, pp. 53-65.

Rodolico, F. 1964, Le pietre delle città d'Italia, Firenze.

Sartori, R., 2002, Pietre e «marmi» di Firenze. Notizie storiche, antiche cave, genesi e presenza dei monumenti, Firenze.

Sembranti, S., 1995, La fabbrica del Duomo di Siena. Restauri consolidativi e comportamento strutturale, "Bullettino Senese di Storia Patria», CII, pp. 63158.

Tragbar, K., 1995, Il campanile del Duomo di Siena e le torri gentilizie della città, «Bullettino Senese di Storia Patria», CII, pp. 159-186.

Valenti, M., 2004, Linsediamento altomedievale nelle campagne toscane. Paesaggi, popolamento e villaggi tra VI X secolo, Firenze.

Vigni, L., 2006, Le volte a crociera della chiesa inferiore del Duomo di Siena, in "Forte Fortuna». Leggere l'arte della Chiesa, a cura di M. Lorenzoni, R. Guerrini, "Quaderni dell'Opera», Anno VII, VIII, IX, nn. 7-9, Fasc. II, pp. $453-456$

\section{APPENDICE}

L'individuazione delle principali tipologie murarie caratterizzanti le diverse fasi costruttive, è basata, per le murature in pietra, sui litotipi, l'apparecchiatura, la lavorazione delle singole bozze o conci, la finitura, la media dei loro valori dimensionali, la media dell'altezza di giunti e letti di posa; per le murature in laterizio si è tenuto conto anche del colore, della "texture» e della foggiatura dei mattoni.

I dati raccolti nel corso della ricerca condotta negli ambienti sottostanti il coro ed il transetto della cattedrale e
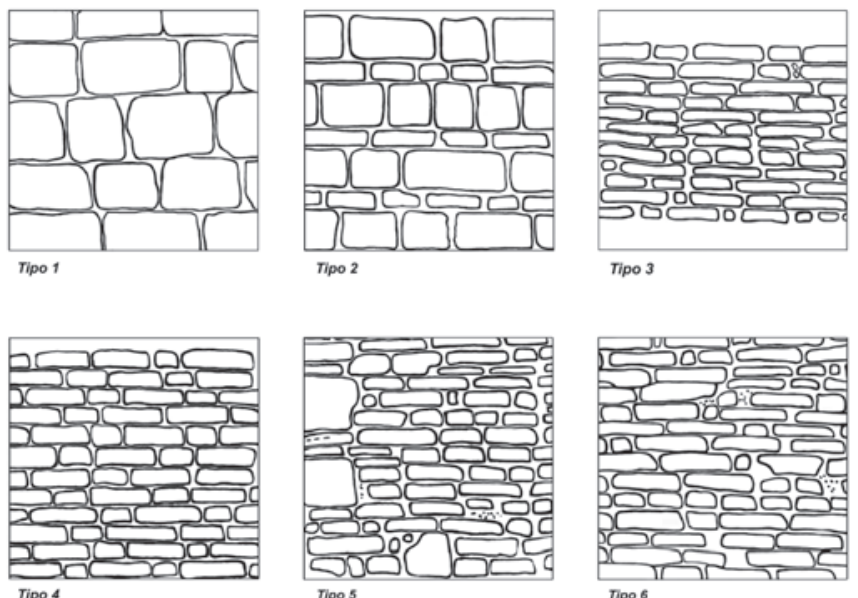

ripos
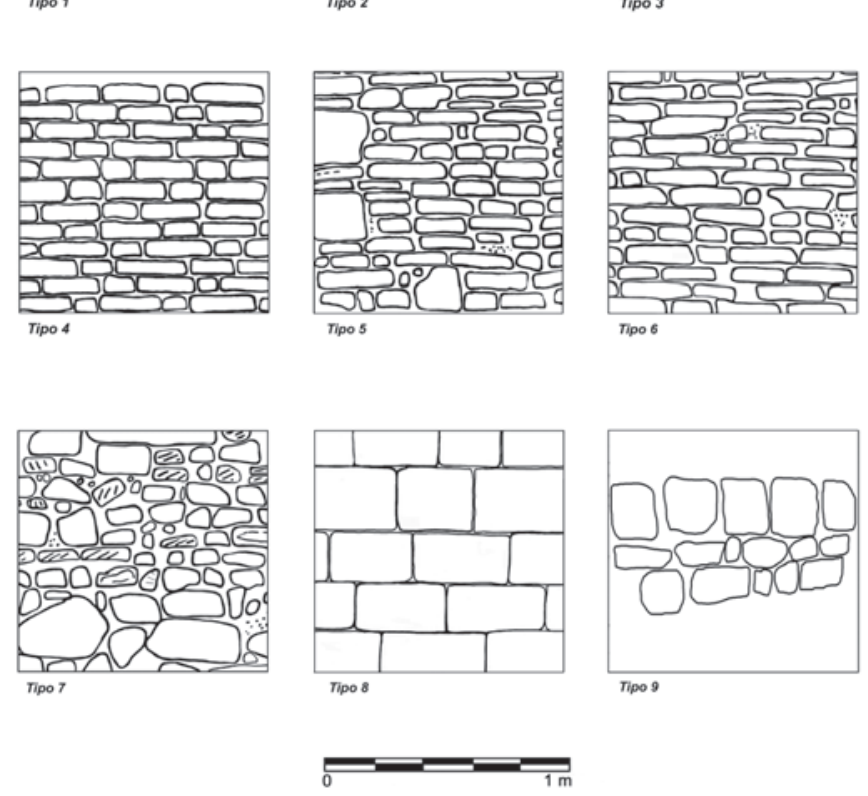

Fig. 21. Tipologie murarie nei sottotetti delle navate laterali sono stati esemplificati nelle schede che seguono ${ }^{64}$ (Fig. 21).

\section{Tipo 1}

Il tipo è visibile nei paramenti murari esterni ed interni del coro e del transetto del Duomo di XII secolo (Fase I). Analoga tipologia muraria si conserva inoltre nel paramento murario interno del campanile - la cui edificazione è databile alla stessa fase - e in una limitata porzione di paramento esterno situato all'interno del sottotetto della navata laterale sud-est.

La muratura è realizzata in conci di calcare cavernoso disposti prevalentemente per orizzontale, con rari elementi per verticale e faccia quadra, su corsi orizzontali e paralleli con altezza variabile tra i 18 e di $22 \mathrm{~cm}$. Rara presenza di zeppe in calcare, lamellari (max. $2 \mathrm{~cm}$ di spessore). Non si segnalano sdoppiamenti di corsi nelle murature appartenenti a questo Tipo.

L'erosione superficiale degli elementi lapidei rende in molti casi difficoltosa l'individuazione dell'eventuale finitura delle superfici, spianate con uno strumento a lama (probabilmente un ascettino). Lo spessore dei giunti $(0,2-$ $1,2 \mathrm{~cm})$ e dei letti di posa $(0,3-1,4 \mathrm{~cm})$ è abbastanza regolare.

Osservazioni: il Tipo è ampiamente attestato a Siena tra l'XI e l'inizio del XIII secolo nell'edilizia civile e religiosa in pietra, caratterizzata dall'utilizzo pressoché esclusivo della cosiddetta "pietra da torre» ${ }^{65}$.

\section{Tipo 2}

Il tipo è attestato nel paramento murario interno di alcuni locali sottostanti il braccio sinistro del transetto trecentesco della cattedrale, edificati all'inizio del XIV secolo (Fase III).

La muratura è realizzata con un'alternanza di due filari di conci di calcare cavernoso e un filare di laterizi disposti in prevalenza di fascia.

I conci, squadrati, sono spianati nella faccia a vista con uno strumento a lama (ascettino); hanno un'altezza regolare, compresa tra i 19 ed i $20 \mathrm{~cm}$. Si nota un periodico, ma non frequente, impiego di mattoni semifusi. Lo spessore dei giunti $(0,2-1 \mathrm{~cm})$ e dei letti di posa $(0,4-$ $1,1 \mathrm{~cm})$ è abbastanza regolare.

\footnotetext{
${ }^{64} \mathrm{E}^{\prime}$ in corso di elaborazione lo studio delle tipologie dei paramenti marmorei della cattedrale. Per una descrizione dettagliata dei paramenti lapidei in marmo di seconda metà XIII secolo e XIV secolo, si veda Causarano 2009; per le tipologie costruttive individuate durante le indagini condotte nella parte absidale del Duomo, si veda anche Causarano et al. 2003, pp. 162-164.

${ }^{65}$ Sulle tipologie murarie in pietra attestate a Siena tra XI e inizio XIII secolo, si veda Bianchi 1988-89; Bianchi 1991, p. 16; Cataldo 2003.
} 
Osservazioni: in ambito urbano questa tipologia è ampiamente attestata a Siena tra la seconda metà del XIII secolo e la prima metà del XIV secolo ${ }^{66}$.

\section{Tipo 3}

Il tipo è attestato nei paramenti esterni dei muri perimetrali del coro e del vano affrescato, databili al XIII secolo (Fase II)

La muratura è realizzata in mattoni posti con un'apparecchiatura in prevalenza per fascia, su filari orizzontali e paralleli. La tessitura muraria, non sempre regolare, utilizza solo periodicamente elementi spezzati. Rara presenza di zeppe in frammenti di laterizio, soprattutto nei letti di posa, per regolarizzare l'altezza del filare. Lo spessore dei giunti $(0,2-0,8 \mathrm{~cm})$ e dei letti di posa $(0,2-1,1 \mathrm{~cm})$ non è sempre regolare.

Osservazioni: i paramenti murari interni al vano affrescato (Ambiente 1) presentano una muratura caratterizzata da laterizi di buona fattura graffiati con uno strumento a lama e disposti su filari perfettamente orizzontali e paralleli.

\section{Tipo 4}

Il tipo è attestato nel paramento murario interno degli ambienti adiacenti il Battistero e, più in generale, è caratteristico delle murature facenti parte dell'ampliamento della cattedrale verso Vallepiatta, databili tra il 1315 e la metà del XIV secolo (Fase IV).

La muratura è realizzata con laterizi posti in opera su filari perfettamente orizzontali e paralleli. Il paramento è contraddistinto da un'apparecchiatura muraria regolare, caratterizzata da laterizi di buona fattura posti in opera alternativamente per fascia e per testa. Lo spessore dei giunti $(0,2-0,9 \mathrm{~cm})$ e dei letti di posa $(0,2-0,8 \mathrm{~cm})$ è sottile e regolare.

Osservazioni: I laterizi utilizzati negli elementi architettonici risultano arrotati e non presentano graffiature. A Siena il tipo è attestato ampiamente nel corso del XIV secolo (BIANCHI 1991, p. 16; CORSI 1991, p. 22).

\section{Tipo 5}

Il tipo è attestato nei paramenti dei setti murari costruiti durante la prima metà del XV secolo (Fase V) al momento dell'abbandono e del definitivo riempimento del vano affrescato (Ambiente 1).

\footnotetext{
${ }^{66}$ Bianchi 1991, p. 16. Questo tipo di muratura è caratterizzato a volte da una variante, realizzata dall'alternanza tra un filare in conci di calcare cavernoso e due o tre filari in mattoni, disposti senza una precisa apparecchiatura.
}

La muratura, priva di fondazioni, presenta paramenti murari in laterizi posti in opera su filari sub-orizzontali e paralleli con un'apparecchiatura in prevalenza per fascia irregolare ma che, con un utilizzo frequente di elementi spezzati, risulta regolare. Lo spessore dei giunti $(0,2-1,5$ $\mathrm{cm})$ e dei letti di posa $(0,3-1,8 \mathrm{~cm})$ è irregolare.

Osservazioni: la muratura riutilizza elementi lapidei (per lo più conci in calcare) e, in alcuni casi, laterizi affrescati provenienti dalla demolizione delle volte dell'Ambiente 1.

\section{Tipo 6}

Il tipo è attestato nel paramento interno delle murature formanti i loculi costruiti tra fine XVI ed inizio XVIII secolo e collocati al passaggio tra coro e transetto, al di sotto del piano pavimentale della cattedrale (Fase VI).

La muratura è realizzata in mattoni disposti su filari orizzontali e paralleli; i laterizi risultano apparecchiati per lo più di fascia e la tessitura muraria è periodicamente regolarizzata con l'utilizzo di elementi spezzati. Lo spessore dei giunti $(0,4-1,2 \mathrm{~cm})$ e dei letti di posa $(0,3-1,4 \mathrm{~cm})$ è irregolare.

\section{Tipo 7}

Il tipo è attestato in un unico caso, nel muro divisorio di epoca moderna (Fase VI) situato nell'ambiente adiacente il Battistero (Ambiente 7).

La muratura è realizzata in ciottoli, pietre spaccate di medie e medio-grandi dimensioni e laterizi per la maggior parte spezzati. Gli elementi sono apparecchiati su filari irregolari, in parte regolarizzati con l'utilizzo di laterizi organizzati su filari di orizzontamento. Si segnala un frequente impiego di zeppe in scaglie di pietra e frammenti di laterizio. Lo spessore dei giunti $(0,5-4,5 \mathrm{~cm})$ e dei letti di posa $(0,6-3,8 \mathrm{~cm})$ è fortemente irregolare.

Osservazioni: questo tipo di apparecchiatura muraria è genericamente databile, in base ai dati di scavo, tra XVII e XVIII secolo.

\section{Tipo 8}

Il tipo è attestato in un unico caso: il paramento esterno della facciata orientale della cattedrale (Ambiente 1), databile all'inizio del XIII secolo (Fase II).

La muratura è realizzata in conci di calcare cavernoso ben squadrati e spianati con l'uso del nastrino, disposti per orizzontale e, più raramente, per faccia quadra, su corsi perfettamente orizzontali e paralleli. Le superfici lapidee sono spianate con una martellina dentata a punte fini mentre il nastrino è realizzato con uno strumento a lama, 
probabilmente uno scalpello piano. Lo spessore dei giunti e dei letti di posa è molto sottile e regolare, di dimensioni non verificabili.

Osservazioni: a differenza delle murature in calcare cavernoso del Tipo 1, il calcare impiegato nella facciata orientale del Duomo è molto compatto e scarsamente vacuolare: ciò ha permesso l'ottima spianatura della faccia a vista dei conci.

\section{Tipo 9}

Il tipo è attestato in un unico caso: il paramento murario esterno dell'abside attribuita all'edificio religioso di inizio XI secolo.
La muratura è in blocchi sbozzati di calcare cavernoso, di dimensioni piuttosto variabili $(\mathrm{h} 15-30 \mathrm{~cm})$, con facce poligonali tendenti frequentemente al rettangolare/ quadrato. Gli elementi sono disposti su corsi sub orizzontali (tendenzialmente paralleli) e di norma per orizzontale con rari elementi in verticale. Si notano rare tracce di lavorazione con uno strumento a punta nella faccia a vista dei blocchi del filare superiore. Lo spessore dei giunti (1$4,5 \mathrm{~cm})$ e dei letti di posa $(1-3,8 \mathrm{~cm})$ è fortemente irregolare.

Recibido: 28 de septiembre de 2009 Aceptado: 10 de noviembre de 2009 